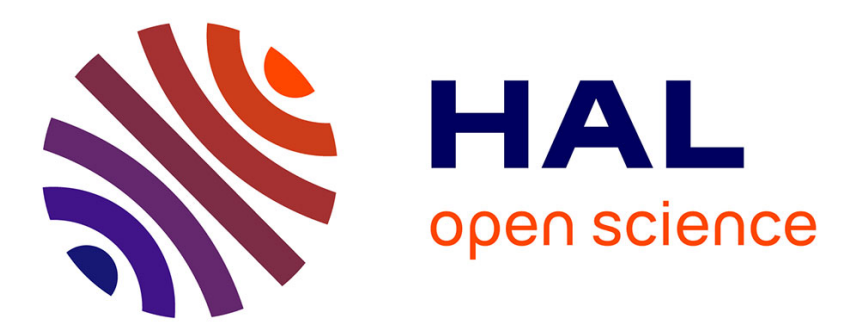

\title{
Multi-objective optimization of gear unit design to improve efficiency and transmission error
}

Emna Ben Younes, Christophe Changenet, Jérôme Bruyère, Emmanuel Rigaud, Joël Perret-Liaudet

\section{- To cite this version:}

Emna Ben Younes, Christophe Changenet, Jérôme Bruyère, Emmanuel Rigaud, Joël Perret-Liaudet. Multi-objective optimization of gear unit design to improve efficiency and transmission error. 2021. hal-03247458

\section{HAL Id: hal-03247458 \\ https://hal.science/hal-03247458}

Preprint submitted on 3 Jun 2021

HAL is a multi-disciplinary open access archive for the deposit and dissemination of scientific research documents, whether they are published or not. The documents may come from teaching and research institutions in France or abroad, or from public or private research centers.
L'archive ouverte pluridisciplinaire HAL, est destinée au dépôt et à la diffusion de documents scientifiques de niveau recherche, publiés ou non, émanant des établissements d'enseignement et de recherche français ou étrangers, des laboratoires publics ou privés. 


\title{
Multi-objective optimization of gear unit design to improve efficiency and transmission error
}

\author{
Emna Ben Younes ${ }^{1,2,3}$, Christophe Changenet ${ }^{1}$, Jérôme Bruyère ${ }^{2}$, Emmanuel Rigaud ${ }^{3}$, \\ Joël Perret-Liaudet ${ }^{3}$ \\ ${ }^{1}$ Université de Lyon, ECAM Lyon, LabECAM, F-69321, France \\ ${ }^{2}$ Université de Lyon, INSA Lyon, CNRS UMR5259, LaMCoS, F-69621, France \\ ${ }^{3}$ Université de Lyon, Ecole Centrale de Lyon, Laboratoire de Tribologie et Dynamique des \\ systèmes, LTDS, UMR5513, ECL, ENISE, ENTPE, CNRS, Ecully, F-69134, France
}

\section{Corresponding author:}

emna.ben-younes@ecam.fr

\begin{abstract}
This study aims to implement multi-objective optimization of a gear unit in order to minimize the power loss and the vibrational excitation generated by the meshing, via a multi-scale approach that extends from gear contact to the complete transmission. All these indicators are closely linked to the macro and micro-geometry definition of the gear pair. The optimization is carried out using a genetic algorithm, namely the Non-Dominated Sorting Genetic Algorithm II (NSGA-II). The design variables chosen for the problem are the pressure angle and the helix angle, as macro-geometry characteristics of the gear, and/or the length and the amount of tooth profile modifications, as micro-geometry characteristics of the gear. Constraints are imposed in order to not exceed a maximum bending stress at the tooth root of the gear and to not fall below a minimum total contact ratio. From the results obtained, it is found that the multi-objective optimization with both micro and macro-geometry parameters simultaneously gives different results than those obtained with macro-geometry first and then micro-geometry parameters. In order to study the importance, or not, to take into account the complete gear unit, a comparison is made between the local power loss generated by gear tooth friction and the total power loss in the single stage gear unit in terms of design variables values.
\end{abstract}

Keywords: multi-objective optimization, heuristics, transmission error, helical gear, tooth profile modification, thermal network, power losses, gear design.

\section{Introduction}

Gears are transmission and power components that have become largely widespread in the most varied fields of mechanical engineering. In many applications, such as machine tools, vehicles, lifting devices, etc., gears are part of the main and auxiliary mechanisms. Additionally, the gear responds favorably to the performance, precision and specific power requirements imposed in the modern mechanical architectures [1].

For that purpose, we should be able to design carefully these gears in order to respond to different aspects. The first aspect is the thermal behavior which is reflected in a minimization of several sources of power losses (tooth friction, bearings, seals and oil churning) in a single stage gear unit which are connected through a thermal network model. The second aspect is the noise and vibration behavior which is reflected in a minimization of the transmission error (TE) which is retained as a major source of gear noise [2], [3]. In order to fulfill these needs, optimization tools are used.

The most used optimization methods are often non-standard and metaheuristic type. These methods may help to obtain an approximate value of the optimal solution and they apply to all 
type of optimization problems. They are inspired by analogies with reality (physics, biology, and ethology). There are two types of optimization in the literature: mono-objective optimization, in which there is only one objective to be optimized and multi-objective optimization, in which there are two or more objectives to be optimized. A Pareto front is obtained in the case of multi-objective optimization. This Pareto front provides engineers with a set of non-comparable optimal solutions, i.e. improving at least one of the objectives compared to the other optimal Pareto points. This allows the engineer to choose the compromise that best fits his need.

Several studies have reported on the optimization of gear design aimed at reducing power loss [4], weight of the gearbox [5], mesh excitation [6],[7] and the different issues encountered along the power drive line like optimal gear ratio and position of shaft axes [8].

It can be noted that many mono-objective optimization approaches have been developed. For example, Buiga and Popa implemented the genetic algorithm (GA) for the mass optimization of a single stage helical gear unit, completed with the sizing of shafts and gear [9]. Chong et al. detailed an optimization algorithm with four steps [10]: i) the user selects the number of reduction stages, ii) the gear ratio at each stage is picked using a random search method, iii) test methods are applied to the gear basic parameters, iv) using the simulated annealing algorithm, the positions of gears are determined to minimize the volume of the gearbox. Conventionally, single-objective optimization of the gear leads to sub-optimal or unacceptable results in relation to other objectives.

Multi-objective processes are increasingly used in gear design optimization, mainly due to the contradictory requirements (one solution may be better than another for some objectives and worse for other objectives). They are interested in optimization of various kinds of gears; namely, bevel gears ([11],[12], [13]), planetary gears ([14],[15],[16],[17]), cylindrical gears e.g. [18]. Let's mention some works that focus on the influence of the design parameters associated with cylindrical gear macro-geometry. A two-stage gear system was studied by Sanghvi et al. using NSGA-II to optimize the volume and load carrying capacity simultaneously [19]. Face width, module, and number of teeth are considered as design variables. Yao considered three different objectives, i.e. center distance, bearing capacity coefficient, and meshing efficiency of the spur gear using NSGA-II algorithm and decision maker which consists to select the optimal solution from Pareto frontier obtained from NSGA-II [20]. Padmanabhan et al. used GA and analytic method, to minimize overall weight and center distance while maximizing the power delivered by the gear pair and efficiency of a spur gear pair, by considering module, tooth number and thickness as design variables [21]. Wei et al. used an adaptive genetic algorithm to minimize gearbox volume, transmission error and contact stress using various design variables [22]. Patil et al. presented the multi-objective optimization of a two-stage helical gearbox [23]. Gearbox volume and total power loss (without taking into account the churning losses) were minimized under mechanical and tribology constraints.

In fact, a gear pair provides theoretically a kinematic input/output law but the presence of defects leads to adverse effects in terms of wear, lifetime and noise [24], [25]. To avoid these major problems, gear micro-geometry modifications are often adopted which correspond to the removal of a few micrometers of material. Profile modifications are introduced to eliminate premature contacts at engagement [26], to reduce the fluctuation of transmission error, and finally to decrease the level of power losses. In this sense, several studies have reported on the optimization of gear micro-geometry parameters, aimed at minimizing transmission error ([25],[27],[28],[29]), efficiency, noise and durability ([30],[31],[32]). Let's quote some of these studies. Ghribi implemented NSGA-II to improve the performance of spur and helical gears using tooth modifications [33]. The gears have been optimized based on several design criteria, 
such as variation of transmission error and/or the product between contact pressure and sliding speed. The impact of tooth modification shape was demonstrated. Garambois et al. carried out a micro/macro geometry optimization to minimize excitation generated by the gear transmission using NSGA-II [6]. The fluctuations of transmission error and mesh stiffness were considered as the objective functions while the mechanical strength, maximum contact pressure, total contact ratio and specific sliding ratio were considered as constraints.

Earlier works have implemented the optimization methods on gear pair and shafts and few of them have been done to optimize the whole power transmission, especially by taking into account the interaction between losses and temperatures. Therefore, there is still few research on the thermal aspects of gear transmissions. In fact, industrial concerns over the last years have mainly focused on problems of mechanical resistance, mass reduction, vibration and noise level, losses, often neglecting the consequences in terms of thermal heating. It should be noted that power loss estimations are heavily dependent on temperature distribution within a gear unit and that specific forecasts are based on models that combine temperature and power loss calculations.

Therefore, this work seeks to implement optimization algorithm, via a multi-scale approach that ranges from gear contact to complete transmission (an enclosed gear drive composed of a onestage helical gear), in order to minimize the power loss and excitations generated by the gear pair from the design parameters of the teeth. NSGA-II algorithm is used as an optimization method. The remainder of this document is organized as follows. The first part presents the system under consideration. Then the transmission error and the sources of power losses are introduced and discussed. NSGA-II algorithm is briefly described in a section by focusing on the design problem (constraints, design variables, etc.). Finally, results of the optimization process are underlined with their corresponding variations.

\section{The studied gear unit}

The system under consideration is a single-stage helical gear unit, presented in Figure 1, equipped with a 29/80 helical gear pair whose characteristics are presented in Table 1 . The pinion and the driven gear are mounted on two parallel shaft lines (the primary and the secondary shafts) supported by deep groove ball bearings [34] (see Figure 1). The whole set is enclosed in a steel right-angled parallelepiped housing $\left(380 \times 280 \times 150 \mathrm{~mm}^{3}\right)$ with mean thickness about $8 \mathrm{~mm}$. The gear unit is splash lubricated by an oil whose properties are given in Table 3. The operating regime is carried out for an engine torque equal to $500 \mathrm{~N} \mathrm{~m}$ with a rotational speed of the input shaft equal to $3000 \mathrm{rpm}$. The oil volume is such that the free surface at rest is located at $15 \mathrm{~mm}$ below the shafts 'axis. All the components of the studied system are made of steel with a Young's modulus $E=2.110^{11} \mathrm{~Pa}$, with Poisson's ratio $v=$ 0.3 and density $\rho=7800 \mathrm{~kg} \mathrm{~m}^{-3}$. 


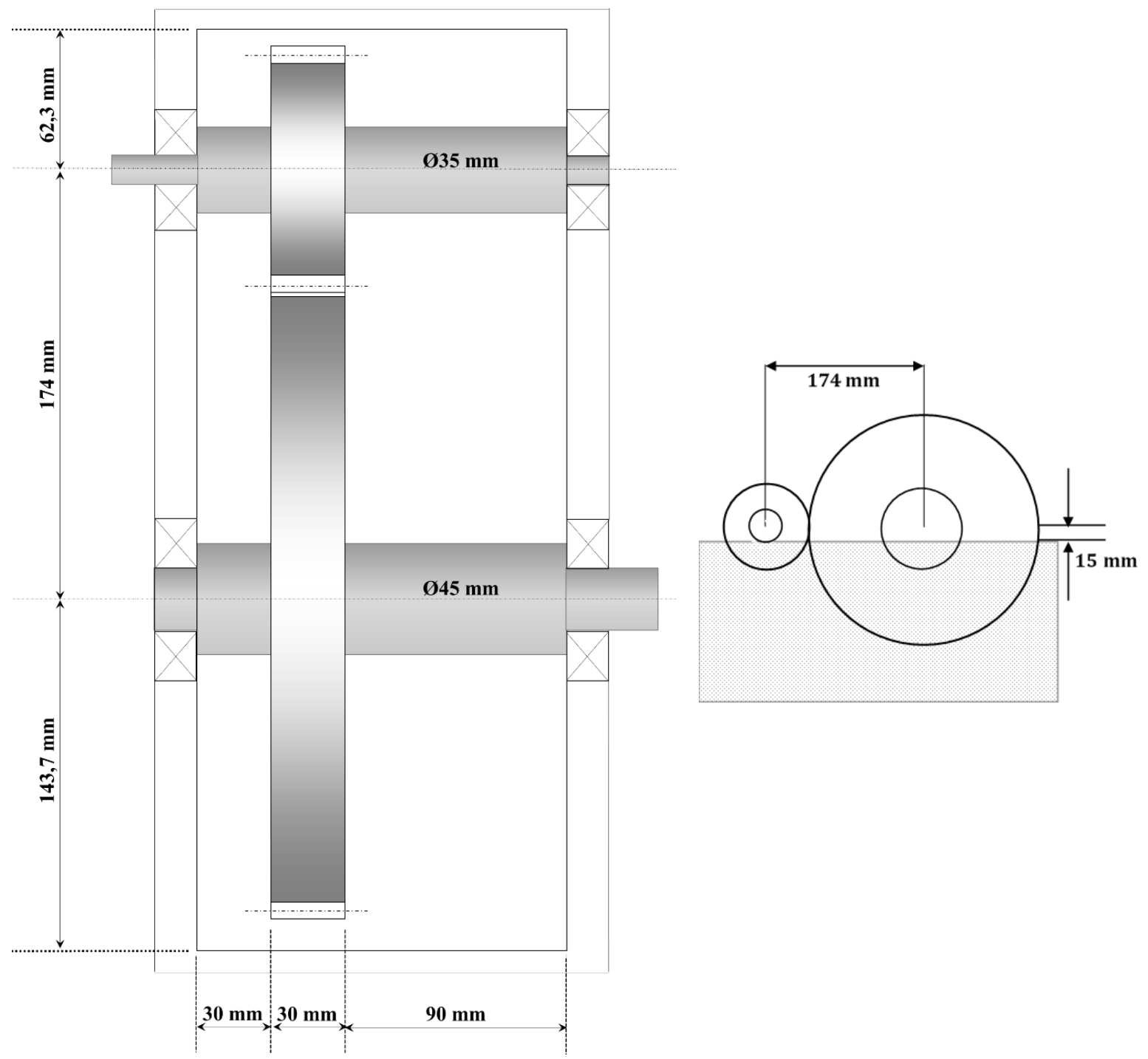

Figure 1. Single stage gear unit

Table 1. Gear macro-geometry characteristics

\begin{tabular}{|c|c|c|}
\hline & Pinion & Wheel \\
\hline Tooth number $Z$ & 29 & 80 \\
\hline Module $m_{0}(\mathrm{~mm})$ & \multicolumn{2}{|c|}{ variable } \\
\hline Tooth face width $b(\mathrm{~mm})$ & \multicolumn{2}{|c|}{30} \\
\hline & Right hand helix & Left hand helix \\
\hline Profile shift coefficient $x$ & 0.2 & -0.2 \\
\hline Addendum coefficient $x_{a}$ & 1.2 & 0.8 \\
\hline Deddendum coefficient $x_{f}$ & 1.05 & 1.45 \\
\hline Center distance $a_{w}(\mathrm{~mm})$ & \multicolumn{2}{|c|}{174} \\
\hline Pressure angle $\alpha_{0}\left(^{\circ}\right)$ & \multicolumn{2}{|c|}{ variable } \\
\hline Helix angle $\beta\left(^{\circ}\right)$ & \multicolumn{2}{|c|}{ variable } \\
\hline
\end{tabular}


Table 2. Gear micro-geometry characteristics

\begin{tabular}{|l|c|}
\hline Longitudinal crowning $(\mu \mathrm{m})$ & 10 \\
\hline Actual depth of modification at tooth tip $E(\mu \mathrm{m})$ & variable \\
\hline Dimensionless extend of profile modification $\Gamma$ & variable \\
\hline
\end{tabular}

Table 3. Lubricant properties

\begin{tabular}{|l|c|}
\hline Kinematic viscosity at $40{ }^{\circ} \mathrm{C}(\mathrm{cSt})$ & 120 \\
\hline Kinematic viscosity at $100^{\circ} \mathrm{C}(\mathrm{cSt})$ & 15.9 \\
\hline Fluid density $\left(\mathrm{kg} \mathrm{m}^{-3}\right)$ & 860 \\
\hline
\end{tabular}

The pressure angle and the helix angle in Table 1, and the depth modification at tooth tips in Table 2 . They represent the decision variables which are likely to vary during the optimization. The macro-geometry parameters are pressure angle $\alpha_{0}$, helix angle $\beta$ and the micro-geometry parameters are the actual depth of modification profile $E$ and the dimensionless extend of profile modification $\Gamma$. These parameters have an impact on the transmission error and the power loss.

\section{Dynamic modeling and transmission error calculation}

The transmission error (TE) is defined as the deviation in the position of the driven gear, relative to its position when gears are geometrically perfect and infinitely rigid [35] and can be expressed as an angular deviation or as a distance by projection at the base plane. Voluntary geometry deviations like tooth modification, involuntary deviations like manufacturing errors [36] (gear misalignment, tooth spacing, run-out error, etc.), elastic deformation and tooth deflections are origins of TE.

To study the behavior of gear transmission, it is necessary to model the physical system using a numerical model. The following part deals with the introduced dynamic model and permit to determine the equation of motion that enables to calculate the transmission error.

\subsection{Dynamic model}

The pinion and the wheel are assimilated into two rigid cylinders each having six degrees of freedom and are connected to each other by an elastic connection (stiffness element) as shown in Figure 3 ([37], [38]). The 12 degrees-of-freedom are introduced as following: three translations $u_{k}, v_{k}, w_{k}$ are the displacements along respectively the $\boldsymbol{U}$-axis according to the center distance, the $\boldsymbol{V}$-axis perpendicular to $\boldsymbol{U}$ and the axial axis $\boldsymbol{Z} . \varphi_{k}, \psi_{k}, \theta_{k}$ are the rotations around $\boldsymbol{U}, \boldsymbol{V}$ and $\boldsymbol{Z}$-axis respectively ( $k=1$ for the pinion and $k=2$ for the wheel) (see Figure 2).

The shaft elements (I, II, III, IV) are modelled using Timoshenko's beam elements [39] with two nodes and six degrees-of-freedom by node as shown in Figure 3. They are connected to concentrated inertial elements modeling the motor $\left(I_{m}=0.2 \mathrm{~kg} \mathrm{~m}^{2}\right)$ and receiver inertia $\left(I_{r}=2.0 \mathrm{~kg} \mathrm{~m}^{2}\right)$. Bearings are modeled by radial and axial stiffness's elements $\left(k_{r 1}=1.510^{8} \mathrm{~N} \mathrm{~m}^{-1}, k_{a 1}=1.210^{8} \mathrm{~N} \mathrm{~m}^{-1}, k_{r 2}=2.510^{8} \mathrm{~N} \mathrm{~m}^{-1}, k_{a 2}=2.210^{8} \mathrm{~N} \mathrm{~m}^{-1}\right)$. The housing is assumed to be infinitely rigid. 


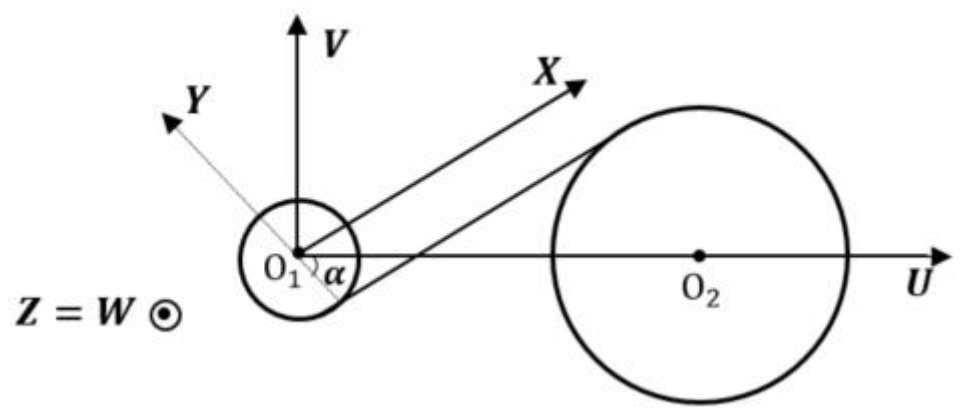

Figure 2. Gear system model such as $\boldsymbol{X}$ is in the direction of the action line and $\boldsymbol{U}$ is in the direction of the line $O_{1} O_{2}$ centers

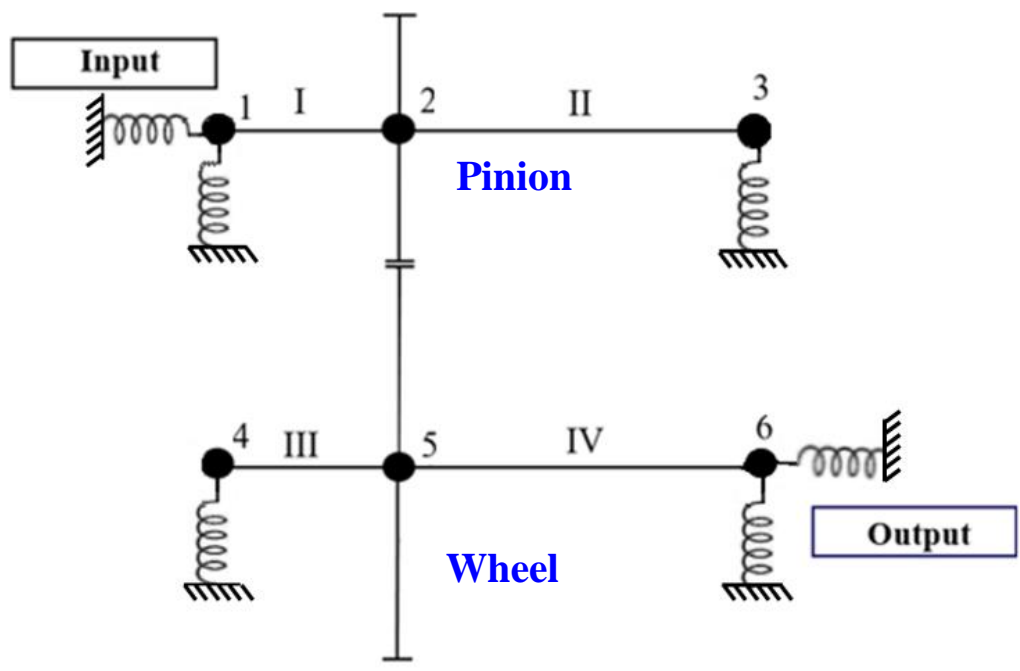

Figure 3. Finite element model of gear transmission: roman numbers represent the shaft elements and arabic numbers represent the nodes

\subsection{Calculation of TE}

This part presents the rules to calculate the transmission error.

In fact, for a perfect and infinitely rigid gear without geometrical deviations, the theoretical input/output law is written as follows:

$$
R_{b 1} \Omega_{1 \text { rigid }}+R_{b 2} \Omega_{2 \text { rigid }}=0
$$

where $R_{b 1}, R_{b 2}$ are the base radius of the pinion and the wheel, $\Omega_{1 \text { rigid }}, \Omega_{2}$ rigid are respectively the rotation speeds of the pinion and the wheel in the ideal case.

However, a real gear never verifies these conditions. It presents a certain number of geometrical defects or shape corrections that cause a deviation between the actual position occupied by the gear and its theoretical position. Then, for a gear with geometrical deviations, new parameters related to the deviation between profiles are introduced. 


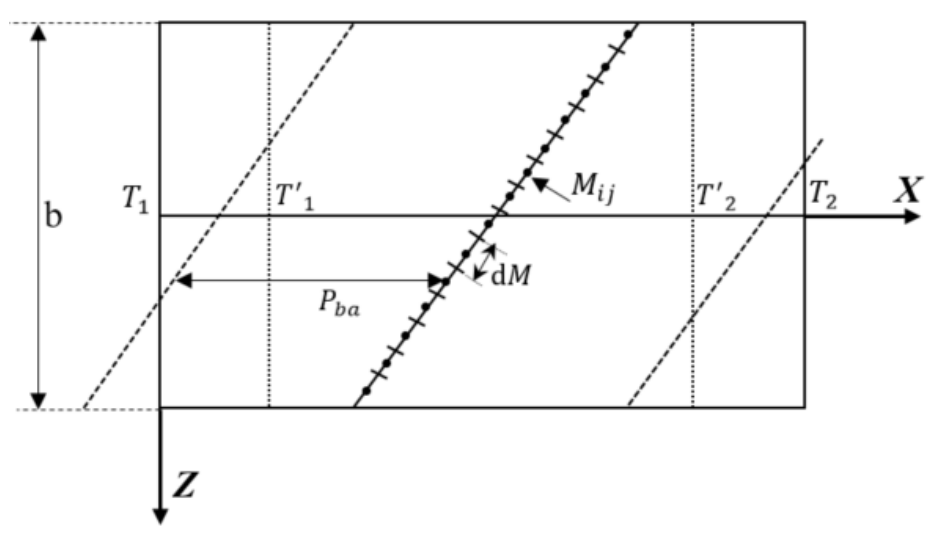

Figure 4. Base plane and contact lines $\left(\boldsymbol{Z}\right.$ : axial direction, $T_{1}, T_{2}$ : points of tangency on pinion and gear base circles, $M_{i j}$ : potential point of contact)

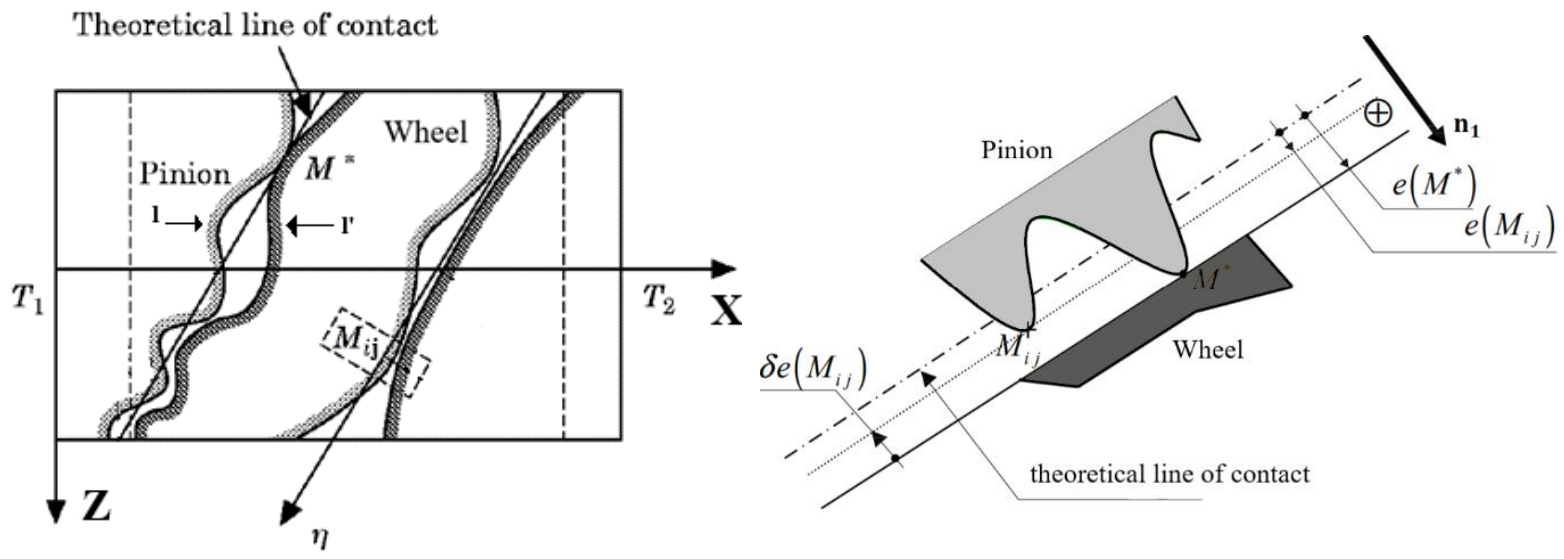

Figure 5. Configuration of the point of contact (inspired by [37])

The contact lines are discretized into several segments (see Figure 4). The geometrical center of each of these segments corresponds to a potential contact point $M_{i j}$ where $i$ represents the line index and $j$ the segment index.

Initial gaps are associated for the pinion and the wheel at each point $M_{i j}$. Each of these deviations are defined by the distance between the real surface and the theoretical surface according to the external normal of the considered profile. The total normal deviation at the point of contact is defined by:

$$
e\left(M_{i j}\right)=e_{1}\left(M_{i j}\right)+e_{2}\left(M_{i j}\right)
$$

with $e_{1}\left(M_{i j}\right), e_{2}\left(M_{i j}\right)$ are the normal deviations according to the theoretical normal at the point $M_{i j}$ on the pinion and the wheel respectively (see Figure 5). This deviation $\left(e\left(M_{i j}\right)\right)$ is positive for an excess of material and negative when some material is withdrawn from the ideal geometry. At any given moment, there is at least one point of contact $\left(M^{*}\right)$ between the rigid teeth which is characterized by a maximum normal deviation $E\left(M^{*}\right)$ such as:

$$
E\left(M^{*}\right)=\operatorname{Max}\left(e\left(M_{i j}\right)\right)
$$

So, as a result of geometrical deviations, there is the appearance of deviations from the ideal case which leads to write following relation linking the rotational speeds in the ideal case and with geometrical deviations: 


$$
\left\{\begin{array}{l}
\Omega_{1}=\Omega_{1 \text { rigid }}+\frac{d \Theta_{1}}{d t} \\
\Omega_{2}=\Omega_{2 \text { rigid }}+\frac{d \Theta_{2}}{d t}
\end{array}\right.
$$

with $\Theta_{1}, \Theta_{2}$ are the angular position deviations of the pinion and the wheel from the ideal case.

From the previous equations and under no-load conditions, the equation linking the rotation speed and the deviations is given by:

$$
R_{b 1} \Omega_{1}+R_{b 2} \Omega_{2}=-\frac{1}{\cos \left(\beta_{b}\right)} \frac{d E\left(M^{*}\right)}{d t}
$$

with $\Omega_{1}, \Omega_{2}$ are respectively the rotation speed of the pinion and the wheel, $\beta_{b}$ is the helix angle on the base plane and $E\left(M^{*}\right)$ is the maximum normal deviation on all potential contact points at a time $t$.

The non-loaded static transmission error (NLTE), corresponding to very low input speed and torque (so that the teeth stay in contact without deformation), results exclusively from gear manufacturing and mounting errors and from the intentional modification of the microgeometry. Its calculation is illustrated for example in [40] and [41]. The time derivative of NLTE is defined as:

$$
\frac{d}{d t}(N L T E)=R_{b 1} \Omega_{1}+R_{b 2} \Omega_{2}=-\frac{1}{\cos \left(\beta_{b}\right)} \frac{d E\left(M^{*}\right)}{d t}
$$

The previous part presented infinitely rigid and non-deformable bodies. To take into account the elasticity, parameters are introduced.

The relative deviation associated with a point $\left(M_{i j}\right)$ on the contact line is defined as the difference between the maximum normal deviation $\left(E\left(M^{*}\right)\right)$ present on the contact line at a given time and the total normal deviation at this point $\left(M_{i j}\right)$. It is noted:

$$
\delta_{e}\left(M_{i j}\right)=E\left(M^{*}\right)-e\left(M_{i j}\right)
$$

In addition to the geometrical deviations, taking into account the elasticity generates a contact action between the pinion (1) and the wheel (2). Each potential contact point $\left(M_{i j}\right)$ is associated with an elementary stiffness $\left(k\left(M_{i j}\right)\right)$ and an equivalent normal deviation $\left(e\left(M_{i j}\right)\right)$ combining the contributions of the pinion and the wheel. Therefore and as previously mentioned and according to [37], the displacements of the pinion and the gear are small so it can be described by displacement screws whose co-ordinates associated are defined by:

$$
\left\{\tau_{k}\right\}=\left\{\begin{array}{c}
\boldsymbol{U}_{\mathbf{k}}\left(O_{k}\right)=u_{k} \boldsymbol{U}+v_{k} \boldsymbol{V}+w_{k} \boldsymbol{Z} \\
\boldsymbol{\omega}_{\mathbf{k}}=\varphi_{k} \boldsymbol{U}+\psi_{k} \boldsymbol{V}+\theta_{k} \boldsymbol{Z}
\end{array}\right\}
$$

where $O_{1}, O_{2}$ are the pinion and gear centers respectively, $k=1$ is associated to the pinion and $k=2$ to the wheel.

The displacement mentioned in equation (8), which represents the degrees of freedom of the pinion and the wheel, is re-arranged in a vector form as:

$$
\boldsymbol{q}^{\mathrm{T}}=\left\langle u_{1}, v_{1}, w_{1}, \varphi_{1}, \psi_{1}, \theta_{1}, u_{2}, v_{2}, w_{2}, \varphi_{2}, \psi_{2}, \theta_{2}\right\rangle
$$

The transmission error (TE) is considered as an overall indicator of the behavior of a gear transmission. It takes into account the deformation of the teeth, as well as the deformations of the gear unit, the shape deviations and the assembly defects. Transmission error (TE) is expressed as a displacement on the base plane [38]: 


$$
\begin{gathered}
T E=R_{b 1}\left[\int_{0}^{t} \Omega_{1}(\xi) d \xi+\theta_{1}\right]+R_{b 2}\left[\int_{0}^{t} \Omega_{2}(\xi) d \xi+\theta_{2}\right] \\
=R_{b 1} \theta_{1}+R_{b 2} \theta_{2}+\text { NLTE }
\end{gathered}
$$

In fact, for each point $\left(M_{i j}\right)$ on the contact line, the combined effect of the infinitesimal displacements of the pinion and the wheel (see 9) introduces a normal deviation $\delta(M)$ compared to the positions of the rigid bodies. To switch from infinitesimal wheel and pinion displacements to $\delta\left(M_{i j}\right)$, the following expression is obtained:

$$
\delta\left(M_{i j}\right)=S\left(M_{i j}\right)^{T} \boldsymbol{q}
$$

with $\boldsymbol{q}$ is the vector of the pinion-gear pair degrees of freedom and $\boldsymbol{S}\left(M_{i j}\right)$ is a structural vector which depending on the gear geometry and expressed by:

$$
S\left(M_{i j}\right)=\left[\begin{array}{c}
n_{1} \\
o_{1} M_{i j} \wedge n_{1} \\
-n_{1} \\
-O_{2} M_{i j}^{\wedge} n_{1}
\end{array}\right]
$$

The deflection $\Delta\left(M_{i j}\right)$ depends both on the normal deviation $\delta\left(M_{i j}\right)$ and on the relative deviation $\delta_{e}\left(M_{i j}\right)$ defined above:

$$
\Delta\left(M_{i j}\right)=\delta\left(M_{i j}\right)-\delta_{e}\left(M_{i j}\right)=\boldsymbol{S}\left(M_{i j}\right)^{T} \boldsymbol{q}-\delta_{e}\left(M_{i j}\right)
$$

The elasticity generates a contact action between the pinion (1) and the wheel (2) given by:

$$
\left\{\begin{array}{cc}
\mathrm{d} \boldsymbol{F}_{1 / 2}\left(M_{i j}\right)=k\left(M_{i j}\right) \Delta\left(M_{i j}\right) \mathrm{d} M \boldsymbol{n}_{\mathbf{1}} & \text { si } \Delta(M)>0 \\
\mathrm{~d} \boldsymbol{F}_{1 / 2}=\mathbf{0} & \text { si } \Delta(M) \leq 0
\end{array}\right.
$$

with $\mathrm{d} \boldsymbol{F}$ is the elemental force of the pinion on the wheel through $\mathrm{d} M, k\left(M_{i j}\right)$ is the mesh stiffness per unit of contact length which can evolve with the load, $\boldsymbol{n}_{\mathbf{1}}$ is the outgoing unit normal of the pinion in $M, \Delta\left(M_{i j}\right)$ is the deflection.

Thus, the resulting total mesh force and moment at the gear center $\left(\mathrm{O}_{2}\right)$ is:

$$
\left\{\tau_{1 / 2}\left(O_{2}\right)\right\}=\left\{\begin{array}{c}
\boldsymbol{F}_{1 / 2}=\int_{L(t)} k\left(M_{i j}\right) \Delta\left(M_{i j}\right) \mathrm{d} M \boldsymbol{n}_{\mathbf{1}} \\
\boldsymbol{M}_{1 / 2}\left(O_{2}\right)=\int_{L(t)} k\left(M_{i j}\right) \Delta\left(M_{i j}\right) \boldsymbol{O}_{2} \boldsymbol{M} \wedge \boldsymbol{n}_{\mathbf{1}} \mathrm{d} M
\end{array}\right.
$$

And, the same for the resulting total mesh force and moment at the pinion center $\left(O_{1}\right)$ but with a negative sign. From equation (15) and (13), the resulting mesh force can be written as follows:

$$
\begin{gathered}
\left\{F_{M_{i j}}\right\}= \\
-\int_{L(t)} k\left(M_{i j}\right) \boldsymbol{S}\left(\boldsymbol{M}_{\boldsymbol{i j}}\right) \boldsymbol{S}\left(\boldsymbol{M}_{\boldsymbol{i j}}\right)^{T} \mathrm{~d} M \boldsymbol{q}+\int_{L(t)} k\left(M_{i j}\right) \delta_{e}\left(M_{i j}\right) \boldsymbol{S}\left(\boldsymbol{M}_{\boldsymbol{i j}}\right) \mathrm{d} M \boldsymbol{q} \\
=-\left[\boldsymbol{K}_{\boldsymbol{G}}(t)\right] \boldsymbol{q}+\boldsymbol{F}_{\boldsymbol{e}}(t)
\end{gathered}
$$

where $\left[\boldsymbol{K}_{\boldsymbol{G}}(t)\right]$ is the time varying gear mesh stiffness matrix, $\boldsymbol{F}_{\boldsymbol{e}}(t)$ is the time varying excitation vector associated with tooth shape modifications and errors.

During the operation of a gear, flexion and foundation of the teeth of both wheels and the local deformations associated with hertzian contact between the teeth occur. These deformations are characterized by a displacement between the teeth along the line of action. This displacement is not constant during the meshing, it depends not only on the transmitted load but also on the 
angular position of the two wheels. So, this approximation can be related to the effort, defined previously through a defined link stiffness along the line of action that evolves over time.

The equation of motion describing the dynamic behavior of the gear transmission can be written as [42],[37]:

$$
[\boldsymbol{M}] \ddot{\boldsymbol{x}}+[\boldsymbol{C}] \dot{\boldsymbol{x}}+[\boldsymbol{K}(t, \boldsymbol{x})] \boldsymbol{x}=\boldsymbol{F}_{\mathbf{0}}+\boldsymbol{F}_{\mathbf{1}}\left(t, \boldsymbol{x}, \delta_{e}(M)\right)+\boldsymbol{F}_{\mathbf{2}}\left(t, \dot{\Omega}_{1,2}\right)
$$

where $\boldsymbol{x}$ is the degree-of-freedom coordinates vector (contains all the degrees of freedom), The mass matrix $[\boldsymbol{M}]$ of the gear unit displayed in figure 1 is obtained by applying the Lagrange equations on the different elements of the transmission. $[\boldsymbol{C}]$ is a damping matrix defined through equivalent modal damping coefficients. A constant modal damping factor $\zeta=0.1$ is retained for all modes. $[\boldsymbol{K}(t, \boldsymbol{x})]$ is the equivalent non-linear time-dependent stiffness matrix (dependent on coordinates of system), $\boldsymbol{F}_{\mathbf{0}}$ is the external load vector, $\boldsymbol{F}_{\mathbf{1}}\left(t, \boldsymbol{x}, \delta_{e}(M)\right)$ is the time-dependent force vector including the contributions of shape modification, $\delta_{e}(M)$ is the relative deviation, $\boldsymbol{F}_{\mathbf{2}}\left(t, \dot{\Omega}_{1,2}\right)$ represents the inertial effects due to unsteady rotational speeds.

The explicit form of the dependency between contact stiffness, state variables and geometry deviations is generally unknown. Hence, the integration of normal contact conditions was taken into account in the step-by-step integration process. Therefore, Newmark's implicit scheme is retained to solve equation (17)coupled to a normal contact algorithm ([37],[43]). 64 time steps are chosen for each mesh period $(\Delta t=0.01 \mathrm{~ms})$. At each time step, two conditions must be verified for evaluating the instantaneous contact length. The loop handles the crushing. If the crushing is positive (i.e. the contact is assured at $M_{i j}$ ) then the stiffness is positive and if the crushing is negative (i.e. there is no contact at $M_{i j}$ ) then the stiffness is zero.

\section{Calculation of power loss}

\subsection{Thermal network}

The thermal network method allows to take into account the interconnection of different heat sources and to determine the bulk temperature of various components of the gear unit [44]. Therefore, the principle of this method is based on the decay of the model (single-stage helical gear unit) into isothermal elements (gears, shafts, bearings etc.). These elements are connected by thermal resistances which depend on the type of heat transfer, i.e. conduction, free or forced convection and radiation [45]. The power losses are calculated by taking into account the temperature of the nodes to insure the thermo-mechanical coupling.

To simulate the steady-state temperature distribution in the studied system, this one has been divided into 14 elements (Table 4). The housing is decomposed into three parts: i) a lower part which contains the oil sump, ii) a lateral part which supports bearings, iii) an upper part. The bearings and the shafts are assumed isothermal and are represented by a sole element. The meshing zone is the small interface between gears where friction occurs. 


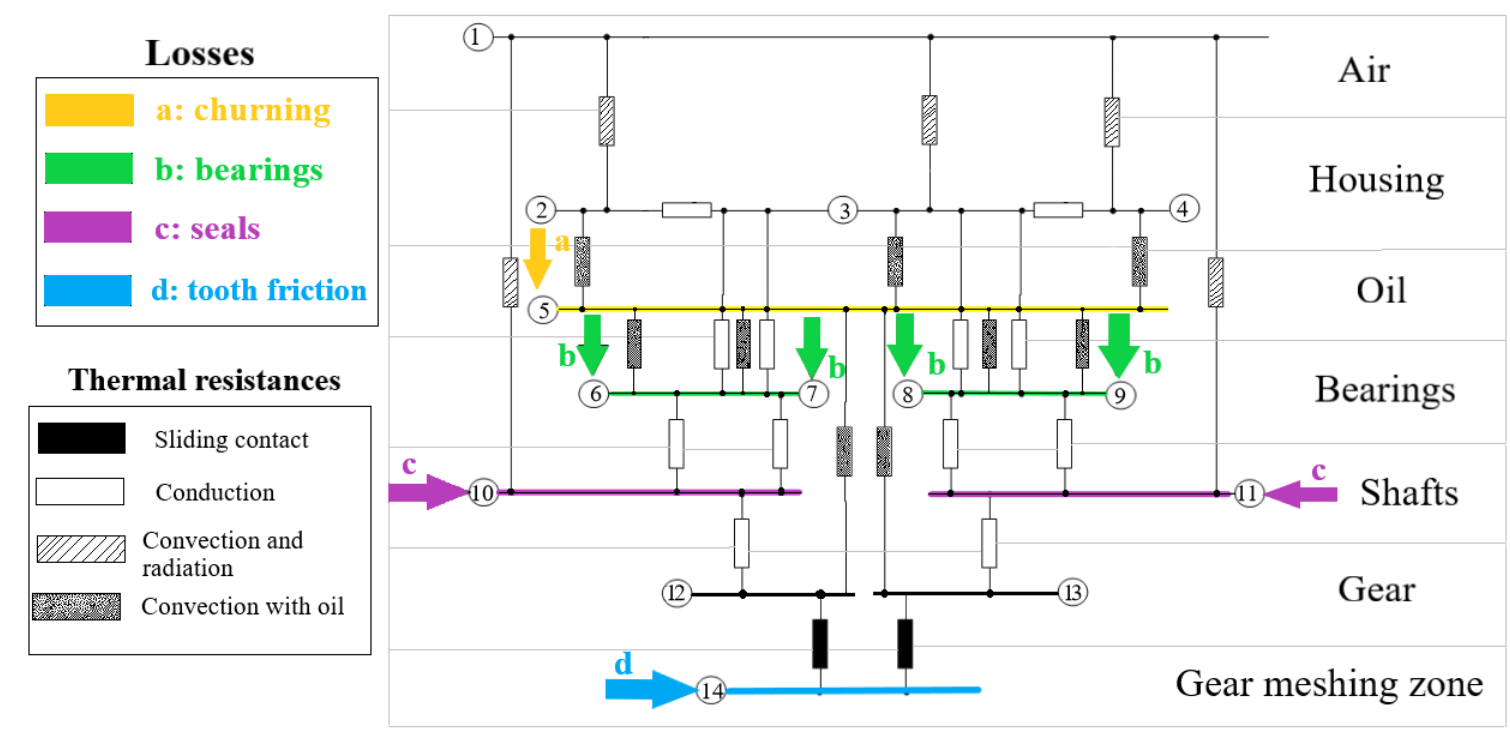

Figure 6. Thermal network for a single stage gear unit

Table 4. Elements of the thermal network

\begin{tabular}{c|c}
\hline NODES & COMPONENTS \\
\hline 1 & Ambient air \\
$2,3,4$ & Housing \\
5 & Oil \\
6,7 & Bearings on primary's shaft \\
8,9 & Bearings on secondary's shaft \\
10 & Input shaft \\
11 & Output shaft \\
12 & Pinion \\
13 & Wheel \\
14 & Meshing of gear teeth \\
\hline
\end{tabular}

It is considered that the housing elements exchange by convection and radiation with the surrounding environment and also by convection with oil through their internal walls. Convection heat-transfer with oil is also taken into account for other elements, such as gears or bearings. Several elements (gears, bearings, shafts) are connected through conduction thermal resistances (see Figure 6). Analytical models used to quantify these different kinds of thermal resistances can be found in previous papers published by Changenet et al. ([44]-[45]).

\subsection{Calculation of power losses}

Different power losses are taken into account as heat sources in the thermal network (symbolized by arrows in Figure 6).

\subsubsection{Rolling- elements bearing losses}

Power losses in the bearings $\left(Q_{\text {bearing }}\right)$ are calculated from Harris' formula [34]. This loss is the sum of a load-dependent power loss in the bearing $\left(Q_{1}\right)$, as a result of elastic deformation and a sliding motion that occurs within the contact zones, and a no-load dependent loss in the bearing $\left(Q_{0}\right)$, affected by hydrodynamic losses in the lubricant. This power loss, injected at nodes 6, 7, 8 and 9 of the thermal network in Figure 6, is given by the formulae below:

$$
Q_{\text {bearing }}=Q_{0}+Q_{1}
$$


with:

No-load dependent power loss $\left(Q_{0}\right)$ given by:

If $\frac{60 \Omega}{2 \pi} v \geq 2000 \mathrm{~mm}^{2} \mathrm{~s}^{-1} \mathrm{~min}^{-1}$

If $\frac{60 \Omega}{2 \pi} v<2000 \mathrm{~mm}^{2} \mathrm{~s}^{-1} \mathrm{~min}^{-1}$

$$
Q_{0}=9.5410^{-7} \Omega f_{0}(\Omega v)^{\frac{2}{3}} d_{m}^{3}
$$

where $v$ is the oil kinematic viscosity, $d_{m}$ is the mean diameter of bearing, $\Omega$ is the rotational speed and $f_{0}$ is a factor that depends on the type of bearing and lubrication.

This work considers that ball bearings are lubricated through the oil sump. Therefore, the selected value of $f_{0}$ is 2 .

Load dependent power loss $\left(Q_{1}\right)$ can be expressed as follows:

$$
Q_{1}=\Omega f_{1} l_{1} d_{m}
$$

where $l_{1}$ is the load applied on the bearings and $f_{1}$ is a constant that depends on bearing type.

The selected value of $f_{1}$ is 0.00075 .

\subsubsection{Shaft seal losses}

This dissipation source is estimated through an empirical relationship proposed by Simrit [46]. Seal losses $\left(Q_{\text {seal }}\right)$ depend on rotational speed $(\omega)$ and shaft diameter $(\varnothing)$. This power loss is applied at nodes 10 and 11 (see Figure 6):

$$
Q_{\text {seal }}=73.4310^{-6} \emptyset^{2} \Omega
$$

\subsubsection{Churning losses}

The studied gear transmission is splash lubricated, i.e., the pinions are immersed in an oil bath. The resulting heat flow is implemented at node 5 in Figure 6. Formulas from Changenet et al. [47] are used to estimate churning losses $\left(Q_{\text {churning }}\right)$ :

$$
Q_{\text {churning }}=\frac{\rho \Omega^{3} S_{m} R_{p}{ }^{3} C_{m}}{2}
$$

where $\rho$ is a fluid density, $S_{m}$ is a submerged surface area, $R_{p}$ is the gear pitch radius and $C_{m}$ is a dimensionless torque depending on the fluid flow regime.

\subsubsection{Tooth friction losses}

This source of dissipation represents a significant part of the global losses in a mechanical transmission. It is associated with the interaction between contact surfaces and the shearing of the lubricant.

The sliding velocity $\left(V_{g}\right)$ and the force $\left(F_{r}\right)$, calculated at point $M_{i j}$ (see Figure 4$)$, vary through the action line. The average of the tooth friction loss $\left(Q_{\text {tooth }}\right.$ friction $)$ is injected to the node 14 in Figure 6 and can be estimated by the following equation:

$$
Q_{\text {tooth friction }}=\sum V_{g}\left(M_{i j}\right) \mathrm{F}_{r}\left(M_{i j}\right) C_{f}
$$

where $C_{f}=0.05$ is the friction coefficient. This value is in accordance with the experimental data from [48]. 
Therefore, in generalized form, the total power losses in the whole transmission $\left(Q_{\text {total }}\right)$ is expressed by the following equation:

$$
Q_{\text {total }}=Q_{\text {bearing }}+Q_{\text {seal }}+Q_{\text {churning }}+Q_{\text {tooth friction }}
$$

\section{The multi-objective optimization problem}

\subsection{Problem formulation}

The aim of this article is to minimize the fluctuation of the transmission error and the power loss of a single-stage helical gear subjected to various constraints via a multi-objective optimization.

Indeed, the Multi-Objective Optimization (MOO) is a part of the mathematical programming dealing with the minimization/ maximization of more than one conflicting objective functions over a feasible set [49]. In this study, we consider two distinct MOO cases:

- In the first one, the two objective functions are the RMS value of transmission error fluctuation $\left(T E_{R M S}\right)$ and tooth friction power loss $\left(Q_{\text {tooth friction }}\right)$ regardless of the thermal network.

- In the second one, the two objective functions are the RMS value of transmission error fluctuation $\left(T E_{R M S}\right)$ and total power loss $\left(Q_{\text {total }}\right)$ which is determined with the interaction between temperature and power losses.

These two cases allow to carry out analyses about the impact of the thermal part on the whole power transmission.

For the studied system, micro-geometry variables and/or macro-geometry variables are considered as the parameters of optimization. Macro-geometry variables are helix angle $\beta$ and pressure angle $\alpha_{0}$. The center distance $a_{w}$ is imposed leading to a variable module $m_{0}$ depending on values chosen for $\beta$. This relation is given by this formula:

$$
m_{0}=\frac{2 a_{w} \cos (\beta)}{Z_{1}+Z_{2}}
$$

Micro-geometry variables $\left(E_{1}, E_{2}, \Gamma_{1}, \Gamma_{2}\right)$ are defined by two parameters for each gear wheel ([38],[50]). $E_{i}$ is the actual depth of modification at tooth tip. Dimensionless parameter $\Gamma_{i}$ is the ratio between the length of relief relative to the length of path of contact. The tip relief modification is linear (see Figure 7).
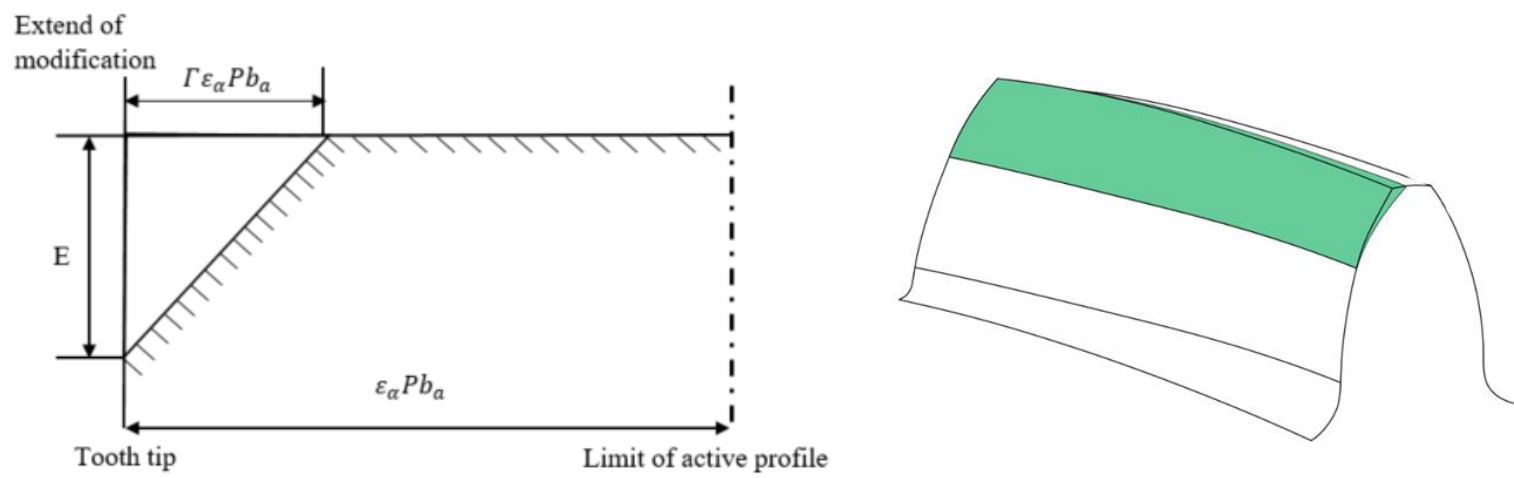

Figure 7. Tooth modification projected on the action line (inspired by [33],[51])

Therefore, the design variables vector is:

$$
\boldsymbol{X}=\left\{\beta, \alpha_{0}, E_{1}, E_{2}, \Gamma_{1}, \Gamma_{2}\right\}
$$


This optimization is carried out under some constraints that must be fulfilled in order to consider an acceptable Pareto front. These constraints are presented below.

Total contact ratio $\left(\varepsilon_{t}\right)$ describes working condition and is an element that influences gear oscillation, noise, strength, rotation and others. It is obtained from the sum of transverse $\left(\varepsilon_{\alpha}\right)$ and overlap $\left(\varepsilon_{\beta}\right)$ contact ratios which are calculated from gear design, macro-geometry parameters and operating center distance and must be greater than 1.2 to ensure continuous transmission of motion.

$$
\begin{gathered}
h_{1}(\boldsymbol{X})=\varepsilon_{t}=\varepsilon_{\alpha}+\varepsilon_{\beta} \\
h_{1}(\boldsymbol{X}) \geq 1.2
\end{gathered}
$$

The calculation of bending stress at the gear tooth root is based on strength of materials. Several correction coefficients are introduced to take into account approximation made and operating conditions. The following constraint based on a streamlined standard formula ISO6336-1 (method B) [52], must be checked for each of the two gears (wheel and pinion):

$$
\begin{gathered}
h_{2}(\boldsymbol{X})=\sigma=\frac{C}{R_{p} b m_{0}} Y_{f} Y_{S} Y_{\beta} Y_{B} Y_{D T} K_{A} K_{V} K_{f \beta} K_{f \alpha} \\
h_{2}(\boldsymbol{X}) \leq \sigma_{\text {lim }}
\end{gathered}
$$

here $C$ is the applied torque, $R_{p}$ is the pitch radius, $b$ is the contact width, $\beta_{b}$ is the base helix angle, $Y_{f}$ is the tooth form factor, $Y_{S}$ is the stress correction factor, $Y_{\beta}$ is the helix angle factor, $Y_{B}$ is the rim thickness factor, $Y_{D T}$ is the tooth depth factor, $K_{A}$ is the application factor, $K_{V}$ is the dynamic factor, $K_{f \beta}$ is the face load factor for tooth-root stress and $K_{f \alpha}$ is the transverse load factor for tooth-root stress.

The intensity of the tooth contact pressure during meshing is the origin of deterioration of tooth surfaces. It is therefore necessary to take this pressure into account in order to evaluate the mechanical strength of the gear. The maximum contact pressure is checked for each angular position:

$$
\begin{gathered}
h_{3}(\boldsymbol{X})=P_{\max } \\
h_{3}(\boldsymbol{X}) \leq P_{\text {lim }}
\end{gathered}
$$

Thus, this study is described by two problems written as follows:

$$
\begin{aligned}
& \text { First MOO problem: }\left\{\begin{array} { c } 
{ \operatorname { m i n } T E _ { R M S } } \\
{ \operatorname { m i n } Q _ { \text { tooth } \text { friction } } }
\end{array} \text { subjected to } \left\{\begin{array}{c}
h_{1}(\boldsymbol{X}) \geq 1.2 \\
h_{2}(\boldsymbol{X}) \leq 500 \mathrm{MPa} \\
h_{3}(\boldsymbol{X}) \leq 1.2 \mathrm{GPa}
\end{array}\right.\right. \\
& \text { Second MOO problem: }\left\{\begin{array} { l } 
{ \operatorname { m i n } T E _ { R M S } } \\
{ \operatorname { m i n } Q _ { \text { total } } }
\end{array} \quad \text { subjected to } \left\{\begin{array}{c}
h_{1}(\boldsymbol{X}) \geq 1.2 \\
h_{2}(\boldsymbol{X}) \leq 500 \mathrm{MPa} \\
h_{3}(\boldsymbol{X}) \leq 1.2 \mathrm{GPa}
\end{array}\right.\right.
\end{aligned}
$$

\section{$\boldsymbol{X} \in S$}

$S$ introduces the boundaries of the decision variables (feasible domain) which are presented in Table 5 . 
Table 5. Search range of decision variables

\begin{tabular}{|l|c|}
\hline \multicolumn{1}{|c|}{ Design variables } & Search range \\
\hline Pressure angle $\alpha_{0}$ & {$\left[15-25^{\circ}\right]$} \\
\hline Helix angle $\beta$ & {$\left[0-30^{\circ}\right]$} \\
\hline Actual depth of modification at tooth tip $E_{1}, E_{2}$ & {$[0-100 \mu \mathrm{m}]$} \\
\hline Dimensionless extend of profile modification $\Gamma_{1}, \Gamma_{2}$ & {$[0-0.5]$} \\
\hline
\end{tabular}

In the result section, these problems will be detailed with the corresponding decision variables.

Contrary to a single-objective optimization, the optimal solution is not a single solution, but rather a set of optimal solutions corresponding to the Pareto front. There are many approaches to solve MOO. The following section presents the retained method and its operation.

\subsection{Description of the retained optimization algorithm}

Metaheuristics are known to be interesting approaches for the solution of MOO. Many authors have adapted those approaches in their work. For instance, the methods of Czyzak and Jaszkiewicz is based on simulated annealing [53], while Hansen uses the tabou search method [54]. Gravel et al. suggest methods based on ant colony optimization for the solution of an industrial scheduling problem [55] and $\mathrm{He}$ et al. use an improved particle swarm method for optimal power flow [56]. It seems, however, that most multiple objective metaheuristic approaches make use of evolutionary methods such as genetic which are well suited to provide good approximations of the Pareto Front ([57],[58]). In fact, an increasing number of approaches exploit the principal of dominance in the Pareto front sense [59]. However, the use of this concept of dominance alone does not guarantee the diversity of the solutions obtained. Therefore, new evolutionary multiple objective algorithms using several mechanisms such as the concept of dominance, niching, elitism, etc. have been implemented ([59], [60]). These algorithms are said to be elitism because they allow the solutions to be memorized during the execution.

Among these algorithms, the most commonly adopted optimization method to solve multiobjective problems is the elitist genetic algorithm of non-dominant sorting NSGA-II and it is implemented in this study [41]. Indeed, NSGA-II is well established due to its efficiency, well testing and diversity preservation and it is a powerful optimization tool [61]. The popularity of NSGA-II means that it has been coded in several computer-programming languages. Many researches cited in their work numerous studies using this algorithm, for example in building design ([42], [43]) and especially in the field of gears ([44], [13])

NSGA-II is characterized by a fast non-dominated sorting technique, an efficient crowding distance assignment approach to rank and select the population fronts, and genetic operators. The flowchart for this method is given in Figure 8 and a brief description of NSGA-II is given after. The NSGA-II algorithm starts with a random initial population $P_{0}$ of $N_{P}$ input variables (with the use of constraints if any) and the objective functions are evaluated. Following function evolution of the individuals at each iteration, the individuals are classified as different ranks based on Pareto-optimal. Then, genetic operators such as tournament selection, arithmetic crossover [45] and uniform mutation, are used to produce an offspring $Q_{0}$, of the same size as $P_{0}$, from the best parents. After creating and evaluating of child population, both parents and offspring are merged to create the mixed population $\left(M_{t}=P_{t} \cup Q_{t}\right)$ at the $\mathrm{t}$-th generation with size $2 N_{p}$. This population is sorted again based on non-domination and crowding distance and only the $N_{P}$ best individuals are selected. Then the new population is selected as parents in the 
next round. The process is repeated until the condition for termination is met (i.e. after a fixed number of iterations or generations) or when the population no longer evolves. The operators of the NSGA-II algorithm are guided by predefined parameters and presented in Table 6 .

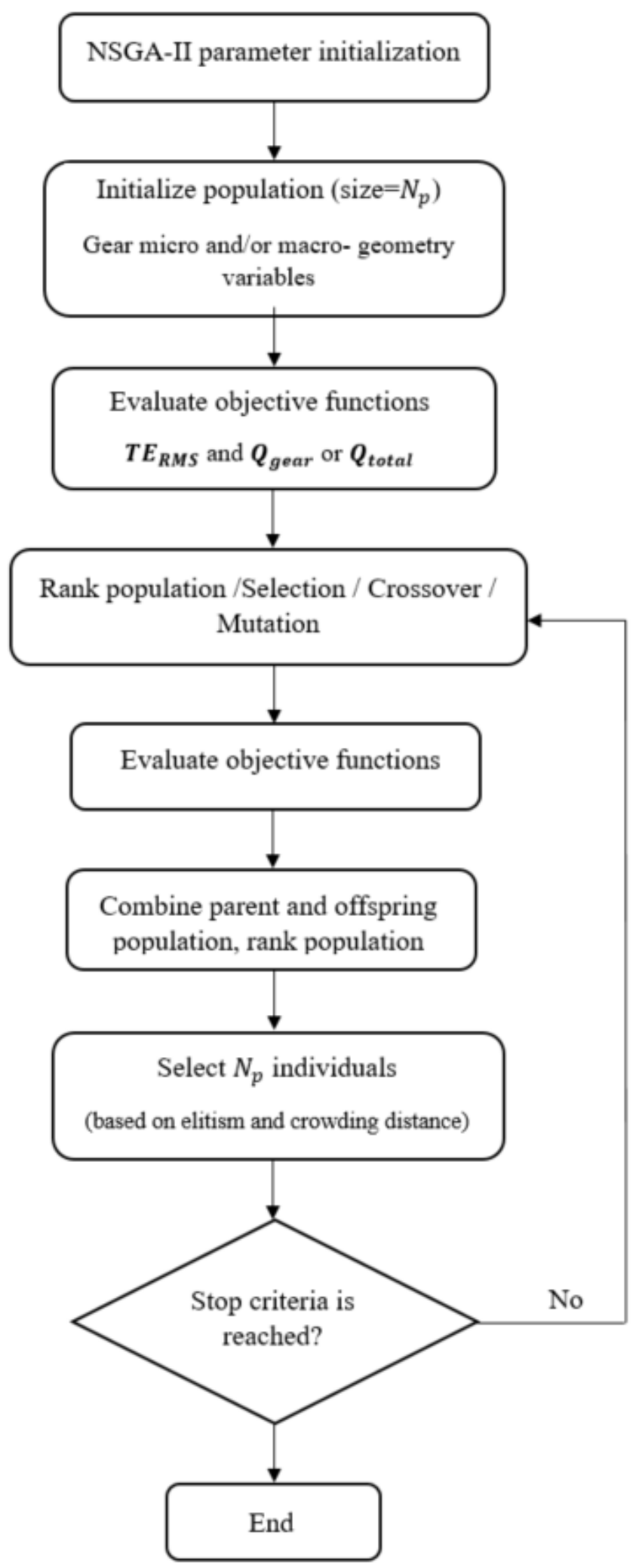

Figure 8. Flowchart of NSGA-II algorithm 
Table 6. NSGA-II parameters used for optimization

\begin{tabular}{|l|c|}
\hline \multicolumn{2}{|c|}{ Parameters of NSGA-II algorithm } \\
\hline \multicolumn{1}{|c|}{ Parameter } & Value \\
\hline Population size & 100 \\
\hline Maximum number of generations & 100 \\
\hline Mutation rate & 0.01 \\
\hline Selection strategy & Tournament selection \\
\hline Crossover type (real) & Arithmetic crossover \\
\hline Mutation type (real) & Uniform mutation \\
\hline
\end{tabular}

Numerous simulations have been performed to find suitable values for these parameters (population size, maximum number of generations, etc.). As an example, Figure 9 shows the evolution of the minimum of $Q_{\text {tooth friction }}$ versus the number of generations for optimization with macro-geometry variables $\alpha_{0}$ and $\beta$. It indicates that 100 generations correspond to a limit up to which no significant change is detected in the simulation performed. Concerning the size of population, 100 individuals are enough to search solutions in the variable domain and allowed to obtain reliable results. Figure 10(a) (respectively Figure 10(b)) presents the number of individuals corresponding to each pressure angle (respectively helix angle) interval for each generation. It shows that there is a variety of pressure angle $\alpha_{0}$ and helix angle $\beta$ values in the initial population (generation 0 ) and the solution converges from generation 90.

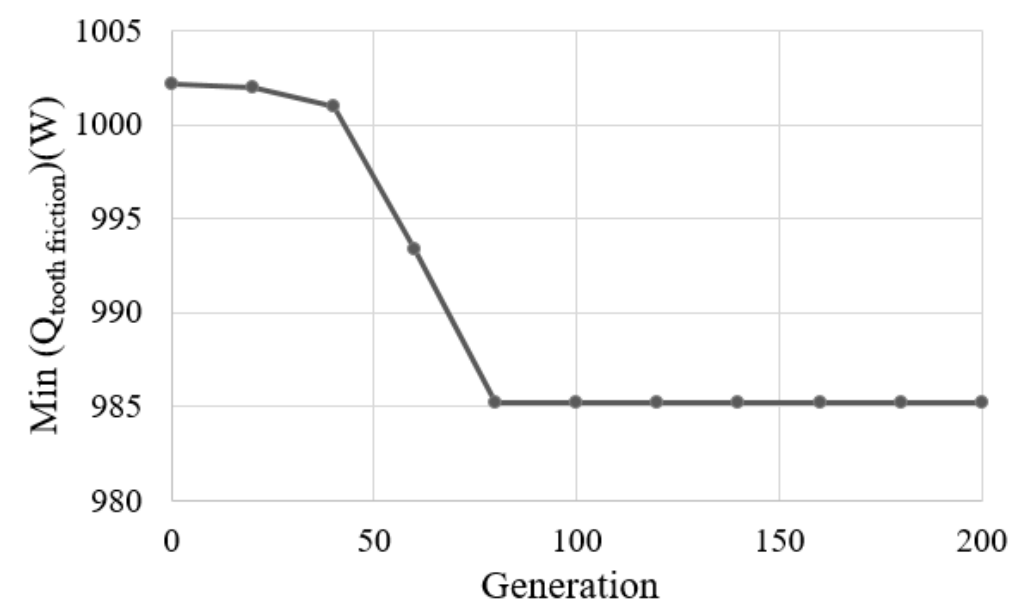

Figure 9. $Q_{\text {tooth friction }}$ evolution vs. number of generation 
(a)

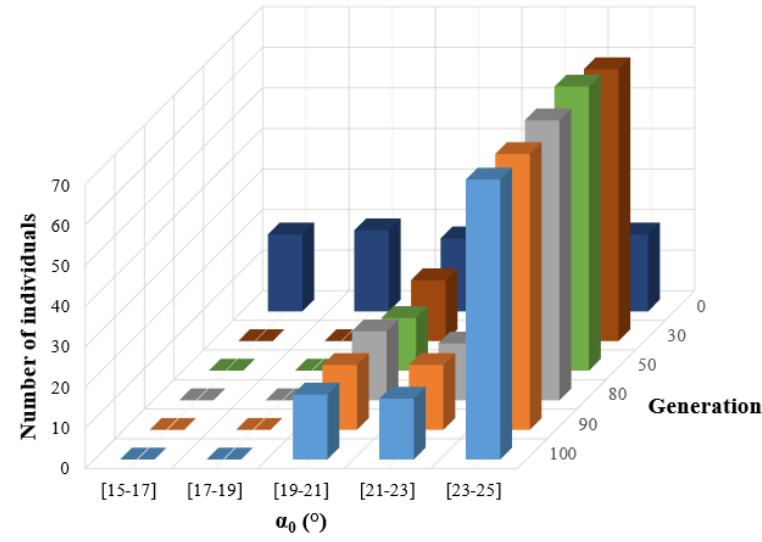

(b)

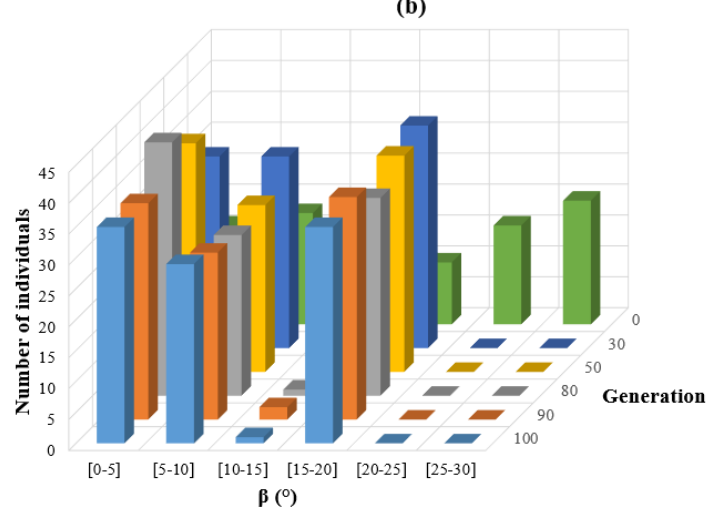

Figure 10. Distribution of pressure angle $\alpha_{0}$ (a) and helix angle $\beta$ (b) of individuals of the Pareto front vs. generation number

\section{Results and discussion}

Before to perform the MOO, power losses and $T E_{R M S}$ are calculated for a reference point with and without profile modification. The geometrical parameters of a reference point are shown in Table 7. The corresponding mechanical and thermal characteristics are given in Table 8 and Figure 11.

Table 7. Geometrical parameters of reference point

\begin{tabular}{|l|c|}
\hline \multicolumn{2}{|c|}{ Reference point } \\
\hline \multicolumn{1}{|c|}{ Parameters } & Value \\
\hline Pressure angle $\left(\alpha_{0}\right)$ & $20^{\circ}$ \\
\hline Helix angle $(\beta)$ & $20^{\circ}$ \\
\hline Module $\left(m_{0}\right)$ & $3 \mathrm{~mm}$ \\
\hline
\end{tabular}

Table 8. Mechanical and thermal characteristics of reference point

\begin{tabular}{|c|c|}
\hline \multicolumn{2}{|c|}{ Reference point } \\
\hline Parameters & Value \\
\hline$Q_{\text {tooth friction }}$ & $1131 \mathrm{~W}$ \\
\hline$Q_{\text {total }}$ & $1896 \mathrm{~W}$ \\
\hline$T_{\text {pinion }}$ & $109.6^{\circ} \mathrm{C}$ \\
\hline$T_{\text {oil }}$ & $96.3^{\circ} \mathrm{C}$ \\
\hline$T E_{R M S}$ & $0.4 \mu \mathrm{m}$ \\
\hline
\end{tabular}




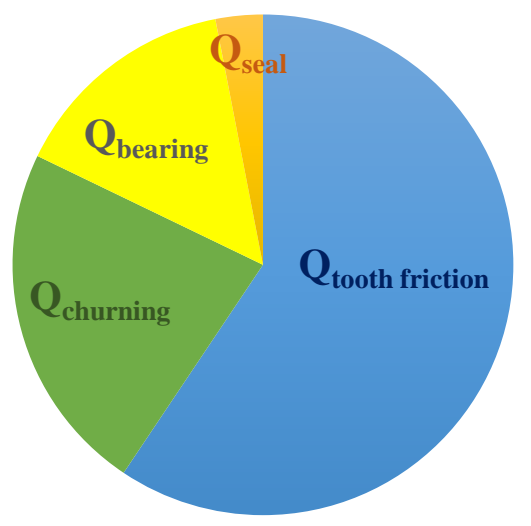

Figure 11: Power loss sources for reference point

The Figure 11 indicates that gear generates more than $80 \%$ including $Q_{\text {tooth friction }}$ and $Q_{\text {churning }}$ of the total power loss. According to the Table 8, it is noticed that for the reference point, the exchange with the environment is sufficient to ensure that $T_{\text {oil }} \leq 100^{\circ} \mathrm{C}$ (in this case $96.3^{\circ} \mathrm{C}$ ). In contrast, the temperature of the gear is higher. As an example the bulk temperature of pinion is around $110^{\circ} \mathrm{C}$.

Thus, a multi-objective optimization is performed in the next section in order to analyze the interest of taking into account the whole transmission.

\subsection{Results with macro-geometry variables}

In this part, two problems are compared using two decision variables. Therefore, the design variables vector is $\boldsymbol{X}_{\mathbf{1}}=\left\{\beta, \alpha_{0}\right\}$ and the two problems to be processed are presented as follows:

$$
\begin{gathered}
\text { First MOO problem: }\left\{\begin{array} { c } 
{ \operatorname { m i n } T E _ { R M S } } \\
{ \operatorname { m i n } Q _ { \text { tooth friction } } }
\end{array} \text { Subjected to } \left\{\begin{array}{c}
h_{1}\left(\boldsymbol{X}_{\mathbf{1}}\right) \geq 1.2 \\
h_{2}\left(\boldsymbol{X}_{\mathbf{1}}\right) \leq 500 \mathrm{MPa} \\
h_{3}(X) \leq 1.2 \mathrm{GPa}
\end{array}\right.\right. \\
\text { Second MOO problem: }\left\{\begin{array} { c } 
{ \operatorname { \boldsymbol { X } _ { \mathbf { 1 } } } \in S } \\
{ \operatorname { m i n } T E _ { R M S } } \\
{ \operatorname { m i n } Q _ { \text { tooth friction } } }
\end{array} \text { Subjected to } \left\{\begin{array}{c}
h_{1}\left(\boldsymbol{X}_{\mathbf{1}}\right) \geq 1.2 \\
\boldsymbol{X}_{2}\left(\boldsymbol{X}_{\mathbf{1}}\right) \leq 500 \mathrm{MPa} \\
h_{3}(X) \leq 1.2 \mathrm{GPa}
\end{array}\right.\right.
\end{gathered}
$$

The results of the optimization of $T E_{R M S}-Q_{\text {total }}$ and $T E_{R M S}-Q_{\text {tooth friction, with two }}$ macro-geometry variables $\beta$ and $\alpha_{0}$, are shown respectively in Figure 12 and Figure 13. 
(a)

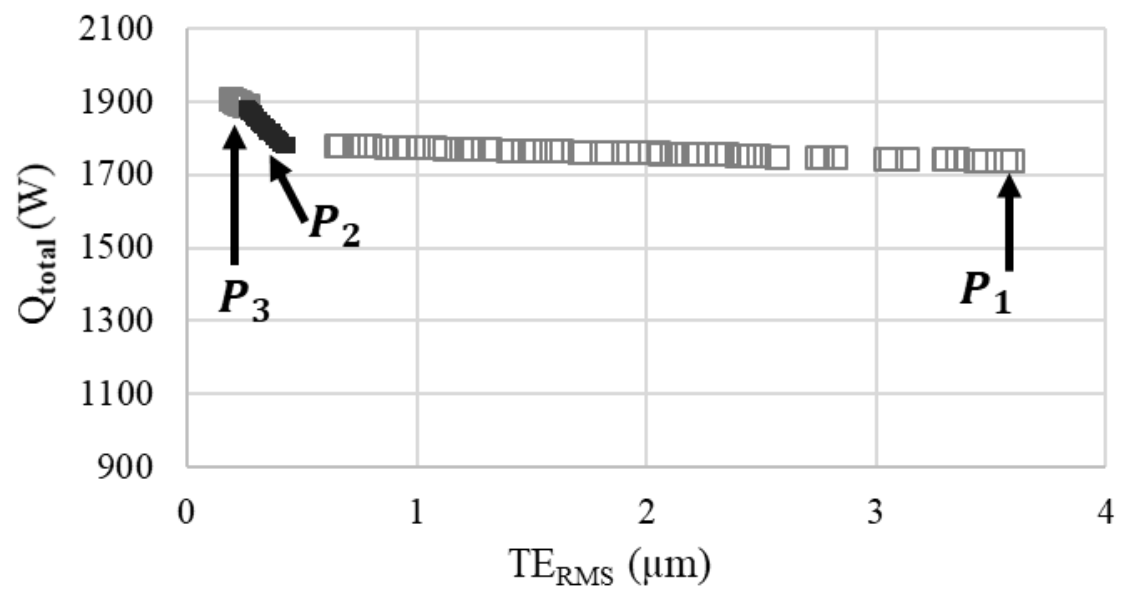

(b)

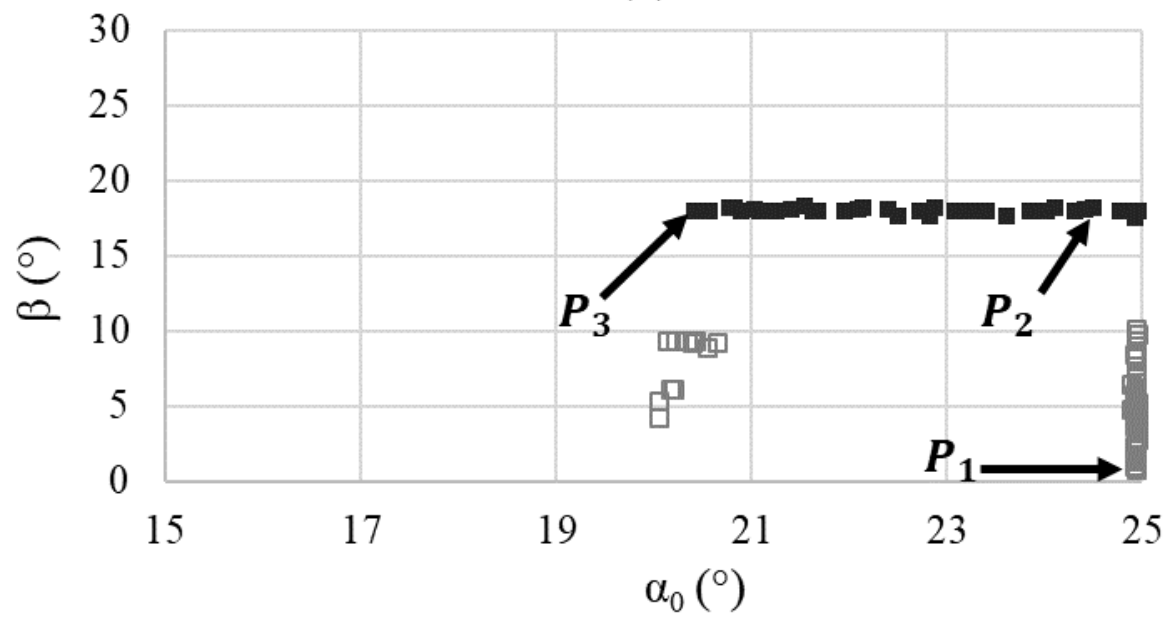

Figure 12. Pareto front $\left(T E_{R M S}-Q_{\text {total }}\right)$ with two design variables $\alpha_{0}, \beta$ (a). Solutions associated to Pareto front (b). $P_{1}, P_{2}, P_{3}$ are specific points. ( $\square$ ) $0.8^{\circ} \leq \beta \leq 10^{\circ}$.

(a) $17.5^{\circ} \leq \beta \leq 18.2^{\circ}$.

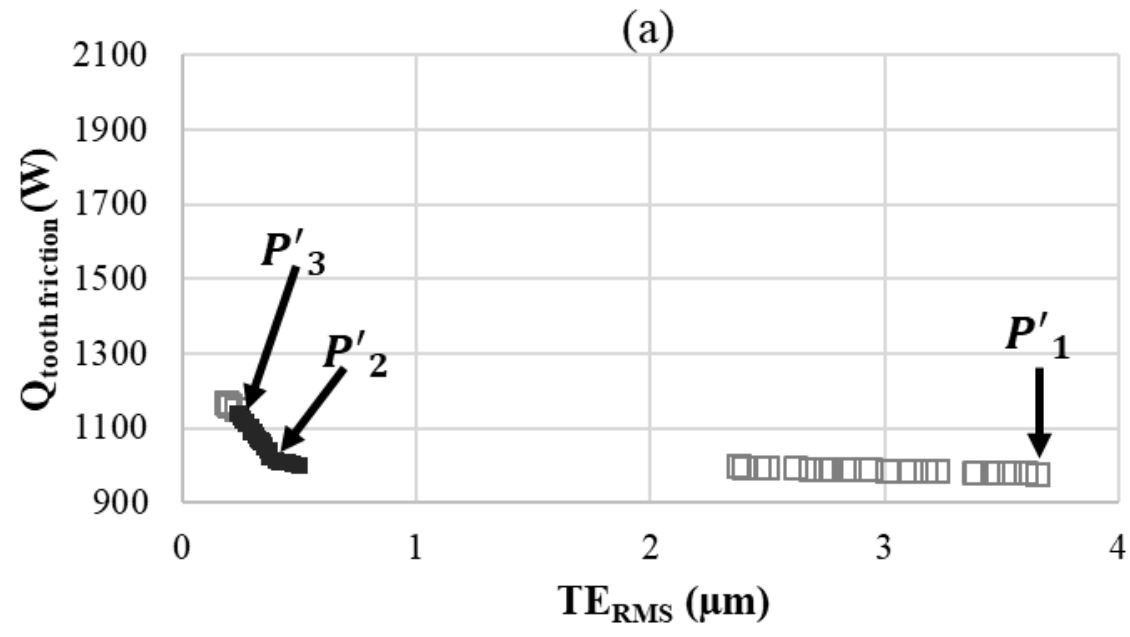


(b)

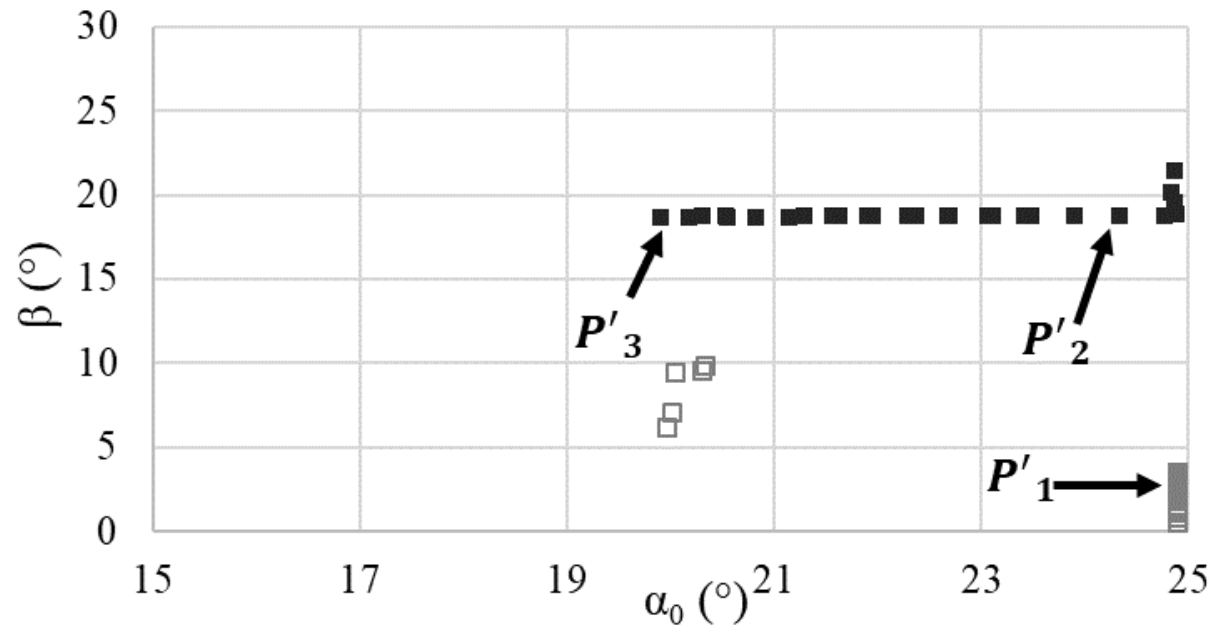

Figure 13. Pareto front $\left(T E_{R M S}-Q_{\text {tooth friction }}\right)$ with two design variables $\alpha_{0}, \beta$ (a). Solutions associated to Pareto front (b). $P_{1}^{\prime}, P^{\prime}{ }_{2}, P^{\prime}{ }_{3}$ are specific points. ( $\square$ ) $0.5^{\circ} \leq \beta \leq 10^{\circ}$. (घ) $18.6^{\circ} \leq \beta \leq 21.4^{\circ}$.

As can be seen in Figure 12(a), the Pareto front firstly shows a significant decrease of a total power losses $Q_{\text {total }}$ (from 1910 to $1780 \mathrm{~W}$ ) without a notable change of the $T E_{R M S}$ (from 0.2 to $0.4 \mu \mathrm{m}$ ). Then, a major variation of $T E_{R M S}$ is observed (from 0.6 to $3.5 \mu \mathrm{m}$ ) at approximatively constant total power losses (from 1780 to $1740 \mathrm{~W}$ ). Figure 13(a) shows a similar behavior with a decrease of the tooth friction power loss $Q_{\text {tooth friction }}$ (from 1170 to $1000 \mathrm{~W}$ ) without notable change of $T E_{R M S}$ (from 0.2 to $0.5 \mu \mathrm{m}$ ) and then a major variation of the $T E_{R M S}$ (from 2.3 to $3.6 \mu \mathrm{m}$ ) at approximatively constant tooth friction power loss $Q_{\text {tooth friction. }}$.

Figure 12(b) and Figure 13(b) show that the sudden change in slope of the Pareto front corresponds to two independent regions in terms of $\beta$ and $\alpha_{0}$ values. The first part of the Pareto front is associated with a variation of $\beta$ in the range $\left[0.5^{\circ}-10^{\circ}\right]$ and a constant value $\alpha_{0}$ equal to the upper limit of the search range $\left(\alpha_{0}=25^{\circ}\right)$. The second part of the Pareto front is associated with a higher and almost constant value of $\beta\left(\beta \in\left[17.5^{\circ}-18.2^{\circ}\right]\right.$ in Figure $12(\mathrm{~b})$ and $\beta \in\left[18.6^{\circ}-21.4^{\circ}\right]$ in Figure 13(b)) and a variation of $\alpha_{0}$ in the range $\left[20^{\circ}-25^{\circ}\right]$. This helix angle $\beta$ value corresponds to an overlap ratio $\varepsilon_{\beta} \approx 1$ and a total contact ratio $\varepsilon_{t} \geq 2$. A difference between the two problems can be noticed because we do not scan the same $\beta$ ranges. The helix angle can reach higher values by focusing on gear pair than in the whole transmission. In fact, taking into account the complete transmission, going up at helix angle $\beta$ has an impact on the one hand, on the immersed surface $\left(S_{m}\right)$ associated with the churning losses and, on the other hand, on the equivalent load applied to the bearings associated with the bearing losses.

The Pareto front is browsed from specific point $P_{3}$ located on the left side, to point $P_{1}$, located on the right side, in the $T E_{R M S}-Q_{t o t}$ optimization. Similar notations for specific points are used for $T E_{R M S}-Q_{\text {tooth friction }}$ optimization, namely $P^{\prime}{ }_{3}$ to $P^{\prime}{ }_{1}$. The features of these specific points are displayed in Table 9. Despite the previous interpretations, it can be observed that the two points $P_{2}$ and $P^{\prime}{ }_{2}$ have almost the same gear characteristics $\left(\beta=18.5^{\circ}, \alpha_{0}=24.5^{\circ}\right)$. Thus, when considering only the macro-geometry parameters $\left(\alpha_{0}, \beta\right)$, optimization performed from tooth friction loss can lead to solution similar to those obtained with optimization performed from total power loss. 
Table 9. Features of specific points

\begin{tabular}{|l|c|c|c|c|c|c|}
\hline \multirow{2}{*}{ Parameters } & \multicolumn{6}{|c|}{ Coordinates of specific points on the Pareto front } \\
\cline { 2 - 7 } & $P_{1}$ & $P_{2}$ & $P_{3}$ & $P_{1}^{\prime}$ & $P_{2}^{\prime}$ & $P^{\prime}{ }_{3}$ \\
\hline$\left[\beta\left(^{\circ}\right), \alpha_{0}\left(^{\circ}\right)\right]$ & {$[0.8,24.9]$} & {$[18.2,24.5]$} & {$[17.9,20.4]$} & {$[0.5,24.9]$} & {$[18.7,24.3]$} & {$[18.7,19.9]$} \\
\hline$\left[E_{1}(\mu \mathrm{m}), E_{2}(\mu \mathrm{m})\right]$ & {$[0,0]$} & {$[0,0]$} & {$[0,0]$} & {$[0,0]$} & {$[0,0]$} & {$[0,0]$} \\
\hline$\left[\Gamma_{1}, \Gamma_{2}\right]$ & {$[0,0]$} & {$[0,0]$} & {$[0,0]$} & {$[0,0]$} & {$[0,0]$} & {$[0,0]$} \\
\hline$\left[T E_{R M S}(\mu \mathrm{m}), Q(\mathrm{~W})\right]$ & {$[3.6,1740]$} & {$[0.4,1790]$} & {$[0.3,1880]$} & {$[3.6,980]$} & {$[0.4,1020]$} & {$[0.2,1140]$} \\
\hline
\end{tabular}

In terms of total losses, the interest of the global model using a thermal network is to describe the temperature distribution. The bulk temperature of pinion $\left(T_{\text {pinion }}\right)$ varies between $108^{\circ} \mathrm{C}$ and $100^{\circ} \mathrm{C}$ for solutions between the specific points $P_{3}$ and $P_{1}$. It is noted that there is not much variation in temperature (only $8^{\circ} \mathrm{C}$ ) since the losses are reduced by $140 \mathrm{~W}$.

\subsection{Results with micro-geometry variables}

In this part, the specific point $P_{2}$, such as $\alpha_{0}=24.5^{\circ}$ and $\beta=18.5^{\circ}$, is chosen from the previous Pareto fronts in order to carry out the micro-geometry optimization with four design variables $\boldsymbol{X}_{2}=\left\{E_{1}, E_{2}, \Gamma_{1}, \Gamma_{2}\right\}$ and compare the two problems below:

$$
\text { First MOO problem: }\left\{\begin{array} { c } 
{ \operatorname { m i n } T E _ { R M S } } \\
{ \operatorname { m i n } Q _ { \text { tooth friction } } }
\end{array} \text { Subjected to } \left\{\begin{array}{c}
h_{1}\left(\boldsymbol{X}_{2}\right) \geq 1.2 \\
h_{2}\left(\boldsymbol{X}_{2}\right) \leq 500 \mathrm{MPa} \\
h_{3}(X) \leq 1.2 \mathrm{GPa}
\end{array}\right.\right.
$$

$$
\text { Second MOO problem: }\left\{\begin{array} { c } 
{ \operatorname { m i n } T E _ { R M S } } \\
{ \operatorname { m i n } Q _ { \text { tooth friction } } } \\
{ \boldsymbol { X } _ { \mathbf { 2 } } \in S }
\end{array} \text { Subjected to } \left\{\begin{array}{c}
h_{1}\left(\boldsymbol{X}_{2}\right) \geq 1.2 \\
h_{2}\left(\boldsymbol{X}_{2}\right) \leq 500 \mathrm{MPa} \\
h_{3}(X) \leq 1.2 \mathrm{GPa}
\end{array}\right.\right.
$$


(a)

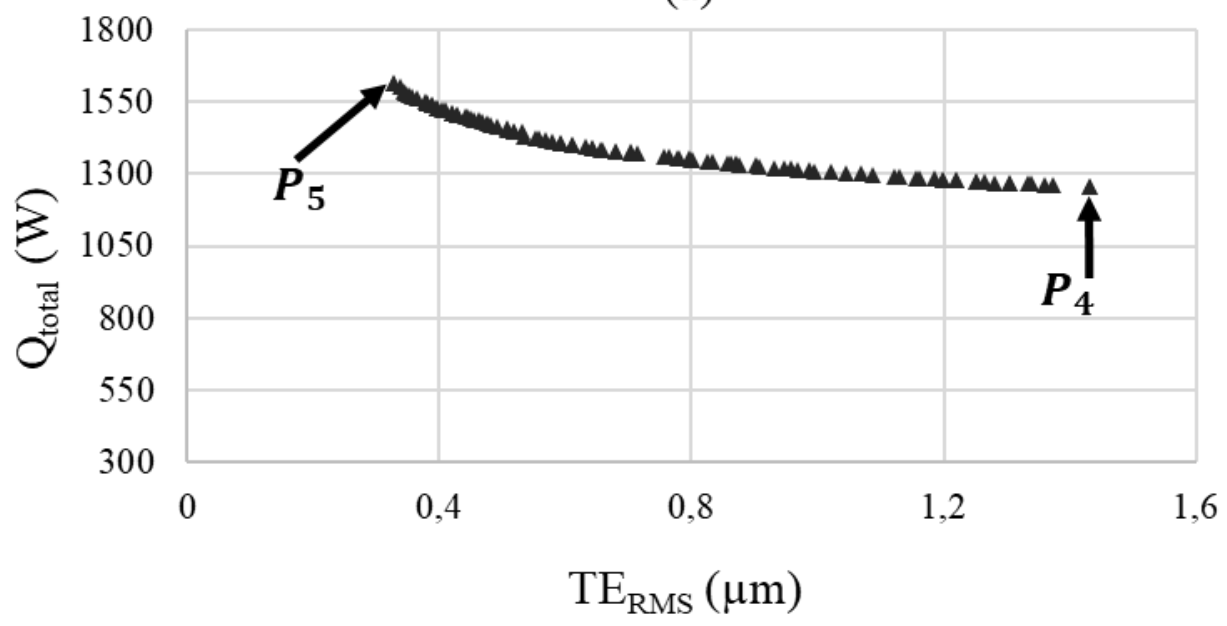

(b)

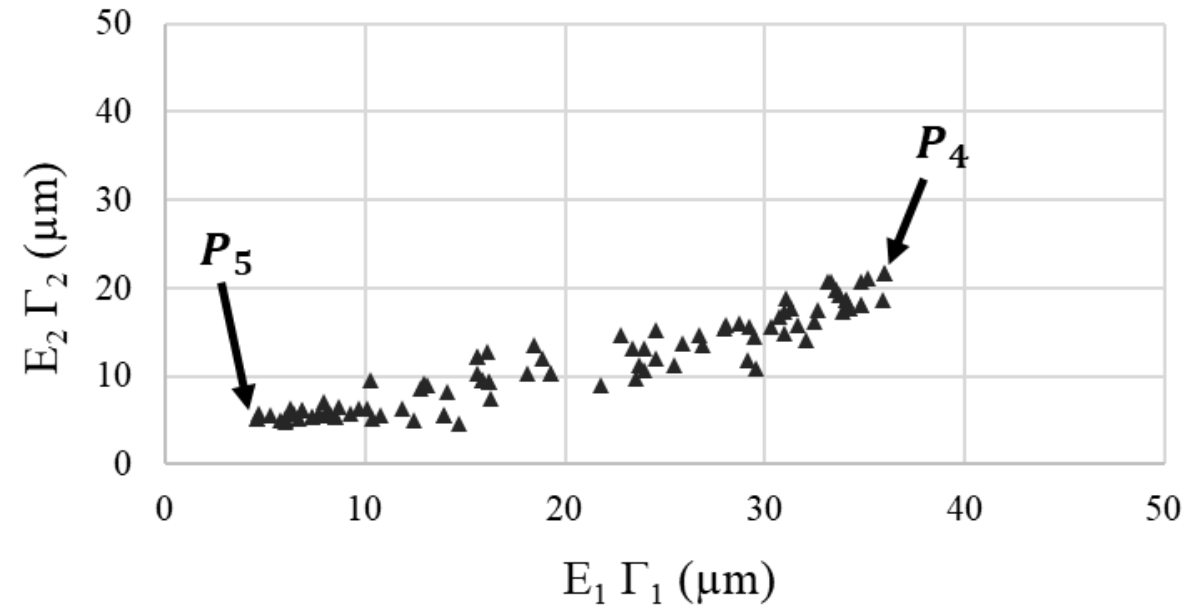

Figure 14. Pareto front $\left(T E_{R M S}-Q_{\text {total }}\right)$ with four design variables $E_{1}, E_{2}, \Gamma_{1}, \Gamma_{2}$ (a). Solutions associated to Pareto front (b). $P_{4}, P_{5}$ are specific points.

(a)

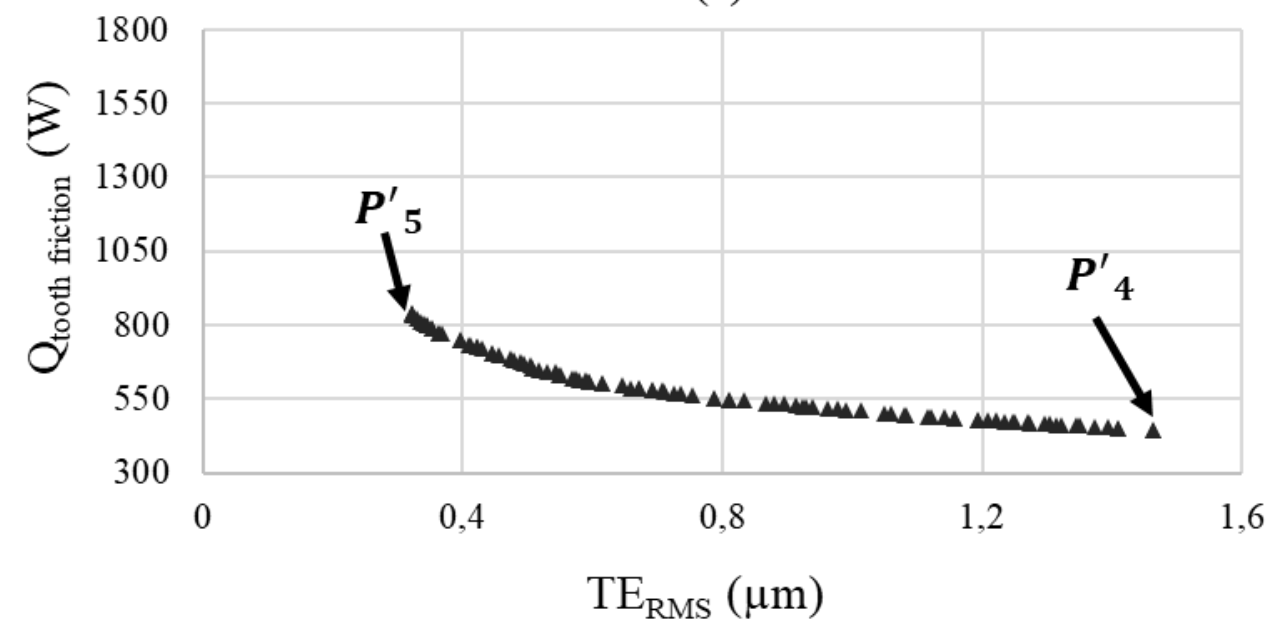


(b)

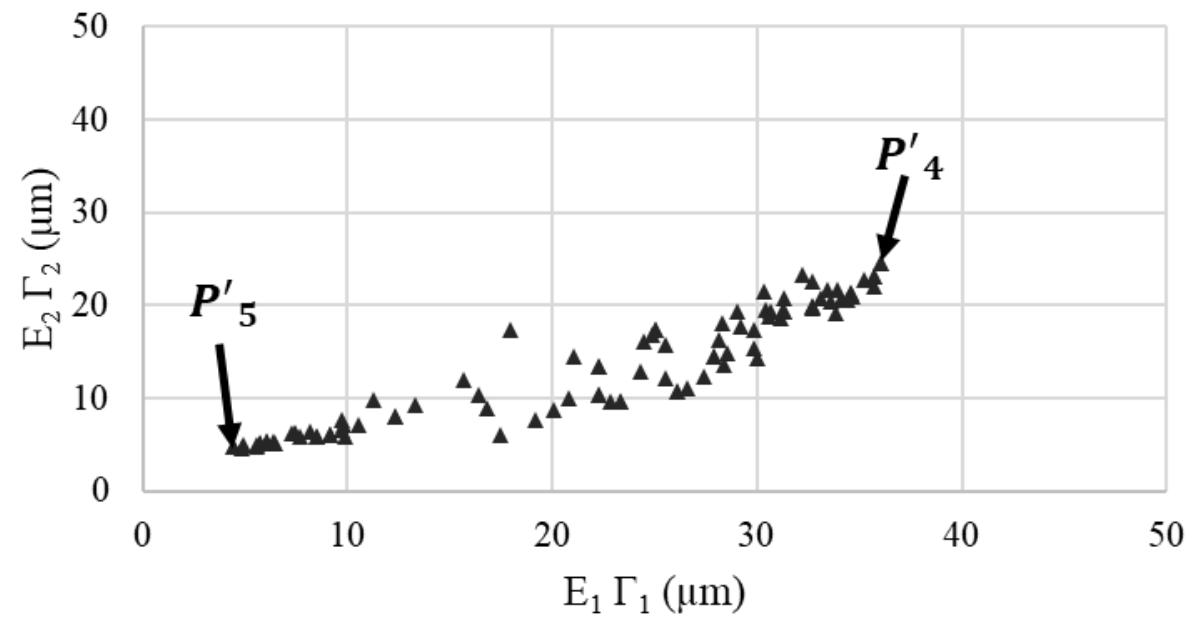

Figure 15. Pareto front $\left(T E_{R M S}-Q_{\text {tooth friction }}\right)$ with four design variables $E_{1}, E_{2}, \Gamma_{1}, \Gamma_{2}$ (a). Solutions associated to Pareto front (b). $P_{4}^{\prime}, P^{\prime}{ }_{5}$ are specific points.

Figure 14(a) and Figure 15(a) show that the two Pareto fronts correspond to continuous evolution of objective functions. From specific points $P_{5}$ to $P_{4}, Q_{\text {total }}$ decreases from 1610 to $1260 \mathrm{~W}$ and, from specific points ${P^{\prime}}_{5}$ to $P^{\prime}{ }_{4}, Q_{\text {tooth friction }}$ decreases from 840 to $440 \mathrm{~W}$, while $T E_{R M S}$ varies from 0.3 to $1.5 \mu \mathrm{m}$ in both cases. Table 10 shows that the specific points situated in each side of the Pareto fronts $\left(P_{5}\right.$ and $P_{4}$, respectively $P^{\prime}{ }_{5}$ and $\left.P^{\prime}{ }_{4}\right)$ have little different values for dimensionless parameters $\Gamma_{1}$ and $\Gamma_{2}\left(0.32 \leq \Gamma_{1} \leq 0.42,0.29 \leq \Gamma_{2} \leq 0.34\right)$. However, specific point $P_{5}$ (respectively $P^{\prime}{ }_{5}$ ) corresponding to minimum $T E_{R M S}$ presents a low amount of profile modification at tooth tip $\left(E_{1}=E_{2}=14 \mu \mathrm{m}\right)$ while specific point $P_{4}$ (respectively $P^{\prime}{ }_{4}$ ) corresponding to minimum total power losses $Q_{\text {total }}$ (respectively tooth friction power losses $Q_{\text {tooth friction }}$ ) presents a large amount of profile modification at tooth tip ( $E_{1}=88 \mu \mathrm{m}$ and $E_{2}=65 \mu \mathrm{m}$, respectively $E_{1}=84 \mu \mathrm{m}$ and $E_{2}=83 \mu \mathrm{m}$ ). It is well observed that there is more profile modifications by focusing on gear pair than in the whole transmission.

Table 10. Features of specific points

\begin{tabular}{|l|c|c|c|c|}
\hline \multirow{2}{*}{ Parameters } & \multicolumn{4}{|c|}{ Coordinates of specific points on the Pareto front } \\
\cline { 2 - 5 } & $P_{4}$ & $P_{5}$ & $P_{4}^{\prime}$ & $P^{\prime}{ }_{4}$ \\
\hline$\left[\beta\left(^{\circ}\right), \alpha_{0}\left(^{\circ}\right)\right]$ & {$[18.5,24.5]$} & {$[18.5,24.5]$} & {$[18.5,24.5]$} & {$[18.5,24.5]$} \\
\hline$\left[E_{1}(\mu \mathrm{m}), E_{2}(\mu \mathrm{m})\right]$ & {$[88,65]$} & {$[14,14]$} & {$[84,83]$} & {$[14,14]$} \\
\hline$\left[\Gamma_{1}, \Gamma_{2}\right]$ & {$[0.4,0.33]$} & {$[0.32,0.33]$} & {$[0.42,0.29]$} & {$[0.32,0.34]$} \\
\hline$\left[T E_{R M S}(\mu \mathrm{m}), Q(\mathrm{~W})\right]$ & {$[1.4,1260]$} & {$[0.3,1610]$} & {$[1.5,450]$} & {$[0.3,840]$} \\
\hline
\end{tabular}

When the Pareto front is browsed from the specific point $P_{5}$ towards the point $P_{4}$, the decrease of total power losses $Q_{\text {total }}$ (from 1610 to $1260 \mathrm{~W}$ ) is mainly due to the decrease of tooth friction losses $Q_{\text {tooth friction }}$ (from 830 to $450 \mathrm{~W}$ ). It results in a decrease of the oil temperature (from 82 to $68^{\circ} \mathrm{C}$ ) leading to an increase of oil viscosity and bearing losses (from 290 to $309 \mathrm{~W}$ ) with an almost constant value of churning losses $Q_{\text {churning }}(436 \mathrm{~W})$ and seal losses $Q_{\text {seal }}(58 \mathrm{~W})$. Therefore, the relative weight of tooth friction losses $Q_{\text {tooth friction }}$ decreases significantly from $51 \%$ of total losses in $P_{5}$ to $36 \%$ in $P_{4}$. Therefore, if there is much profile modification such in gear pair, there is indeed a reduction of $Q_{\text {tooth friction }}$ unless behind that 
the gear unit will be colder and this will impact the losses independent of the load. This result shows the importance of taking account the whole gear unit and all sources of power losses.

\subsection{Results with micro and macro-geometry variables}

This part does not deal with the comparison between the two problems but it is concerned with the optimization of the entire mechanical transmission. So, the design variables vector is $\boldsymbol{X}=$ $\left\{\beta, \alpha_{0}, E_{1}, E_{2}, \Gamma_{1}, \Gamma_{2}\right\}$ and the problem to be treated is:

$$
\left\{\begin{array} { l } 
{ \operatorname { m i n } T E _ { R M S } } \\
{ \operatorname { m i n } Q _ { \text { total } } }
\end{array} \text { Subjected to } \left\{\begin{array}{c}
h_{1}(\boldsymbol{X}) \geq 1.2 \\
h_{2}(\boldsymbol{X}) \leq 500 \mathrm{MPa} \\
h_{3}(\boldsymbol{X}) \leq 1.2 \mathrm{GPa}
\end{array} \quad \boldsymbol{X} \in S\right.\right.
$$

Figure 16 displays the Pareto front for $T E_{R M S}-Q_{\text {total }}$ with six design variables $\left(\alpha_{0}, \beta, E_{1}, E_{2}, \Gamma_{1}, \Gamma_{2}\right)$. It shows a continuous evolution of the objective functions with a variation of $Q_{\text {total }}$ (from 1850 to $1240 \mathrm{~W}$ ) and variation of $T E_{R M S}$ (from 0.12 to $1.55 \mu \mathrm{m}$ ). Values for helix angle $\beta$ are almost constant for the whole Pareto front $\left(17.1^{\circ} \leq \beta \leq 17.4^{\circ}\right)$. This helix angle $\beta$ value corresponds to an overlap ratio $\varepsilon_{\beta} \approx 1$. When the Pareto front is browsed from the specific point $P_{8}$ towards the point $P_{6}$, an increase of pressure angle $\alpha_{0}$ is firstly observed (from $15.4^{\circ}$ at $P_{8}$ to $22.7^{\circ}$ at $P_{7}$ ) contributing to a $T E_{R M S}$ value less than $0.4 \mu \mathrm{m}$ as shown in Figure 17. This range is associated to small profile modifications at tooth tip $\left(E_{1} \Gamma_{1} \leq 10 \mu \mathrm{m}\right.$, $\left.E_{2} \Gamma_{2} \leq 5 \mu \mathrm{m}\right)$. Then, the pressure angle is almost constant between $P_{7}$ and $P_{6}\left(\alpha_{0} \approx 23^{\circ}\right)$ while a large variation of profile modifications at tooth tip is observed (from $E_{1} \Gamma_{1}=10$ to $40 \mu \mathrm{m}$ and from $E_{2} \Gamma_{2}=5$ to $20 \mu \mathrm{m}$ ) leading to a decrease of $Q_{\text {total }}$ and an increase of $T E_{R M S}$.

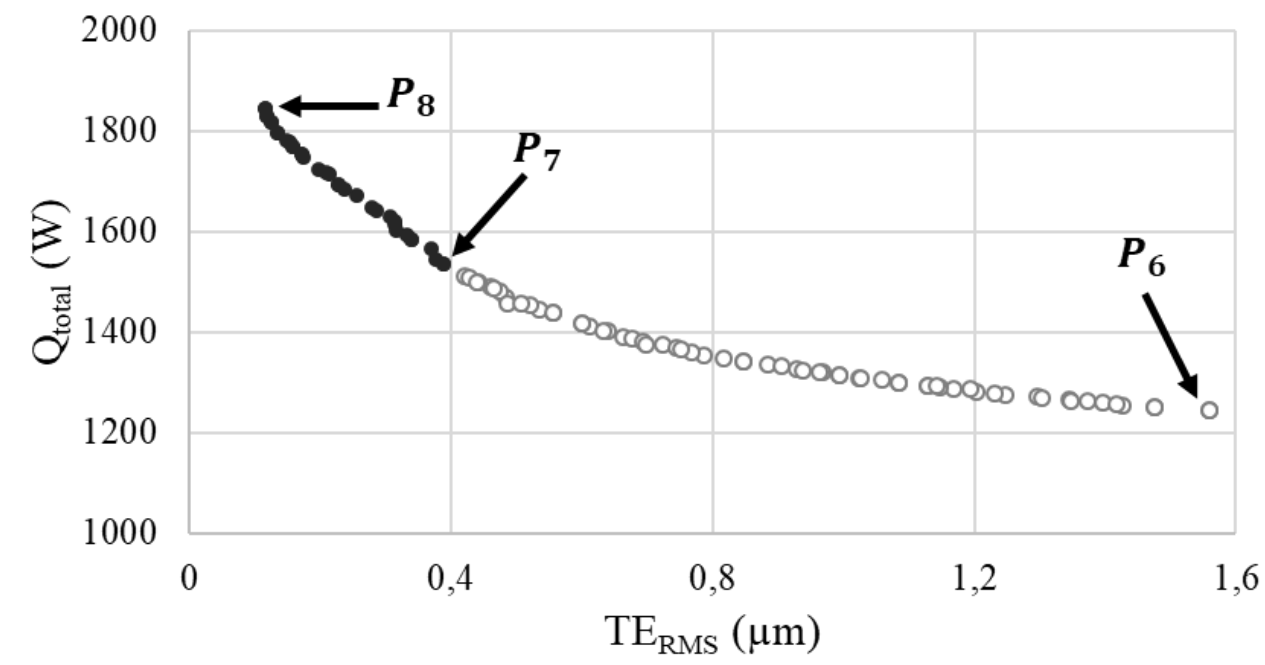

Figure 16. Pareto front $\left(T E_{R M S}-Q_{\text {total }}\right)$ with six design variables. $P_{1}, P_{2}, P_{3}$ are specific points. (•) $15.4^{\circ} \leq \alpha_{0} \leq 22.7^{\circ}$. (০) $\alpha_{0}>22.7^{\circ}$. 
Table 11: Features of specific points

\begin{tabular}{|l|c|c|c|}
\hline \multirow{2}{*}{ Parameters } & \multicolumn{3}{|c|}{ Coordinates of specific points on the Pareto front } \\
\cline { 2 - 4 } & $P_{6}$ & $P_{7}$ & $P_{8}$ \\
\hline$\left[\beta\left(^{\circ}\right), \alpha_{0}\left({ }^{\circ}\right)\right]$ & {$[17.4,23.2]$} & {$[17.2,22.7]$} & {$[17.3,15.4]$} \\
\hline$\left[E_{1}(\mu \mathrm{m}), E_{2}(\mu \mathrm{m})\right]$ & {$[85,56]$} & {$[21,18]$} & {$[82,16]$} \\
\hline$\left[\Gamma_{1}, \Gamma_{2}\right]$ & {$[0.46,0.34]$} & {$[0.35,0.27]$} & {$[0.35,0.22]$} \\
\hline$\left[T E_{R M S}(\mu \mathrm{m}), Q(\mathrm{~W})\right]$ & {$[1.55,1240]$} & {$[0.37,1550]$} & {$[0.11,1850]$} \\
\hline
\end{tabular}

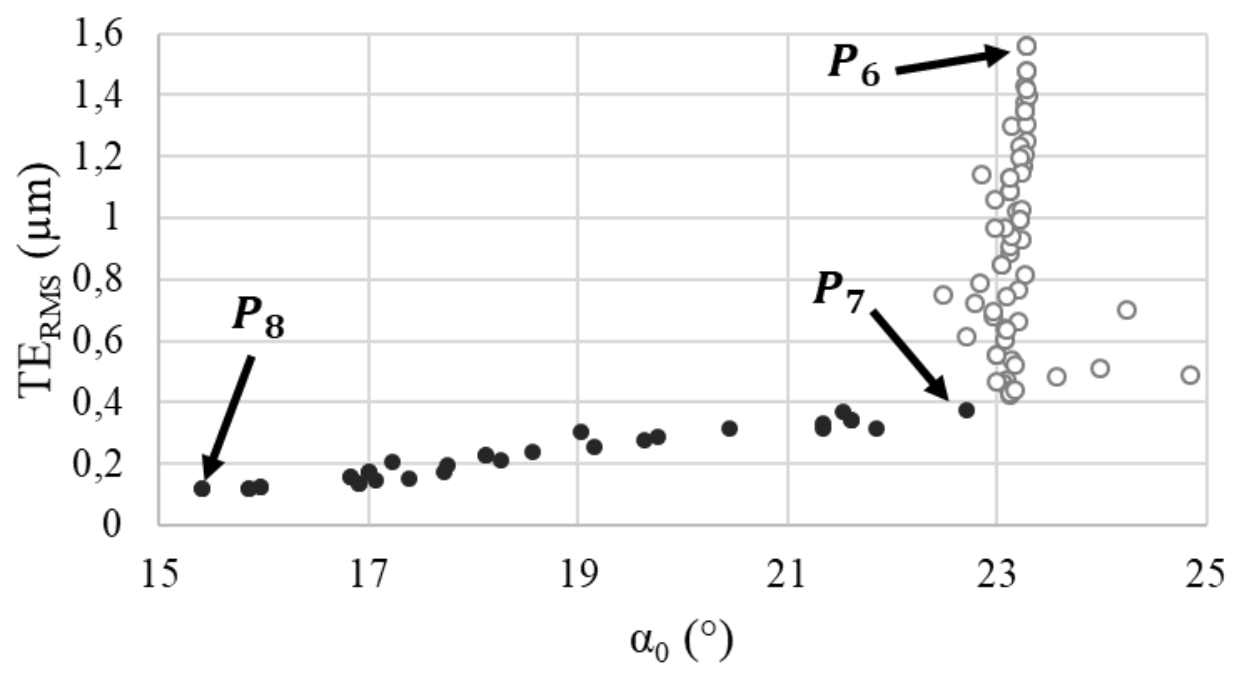

Figure 17. $T E_{R M S}$ evolution as a function of pressure angle 

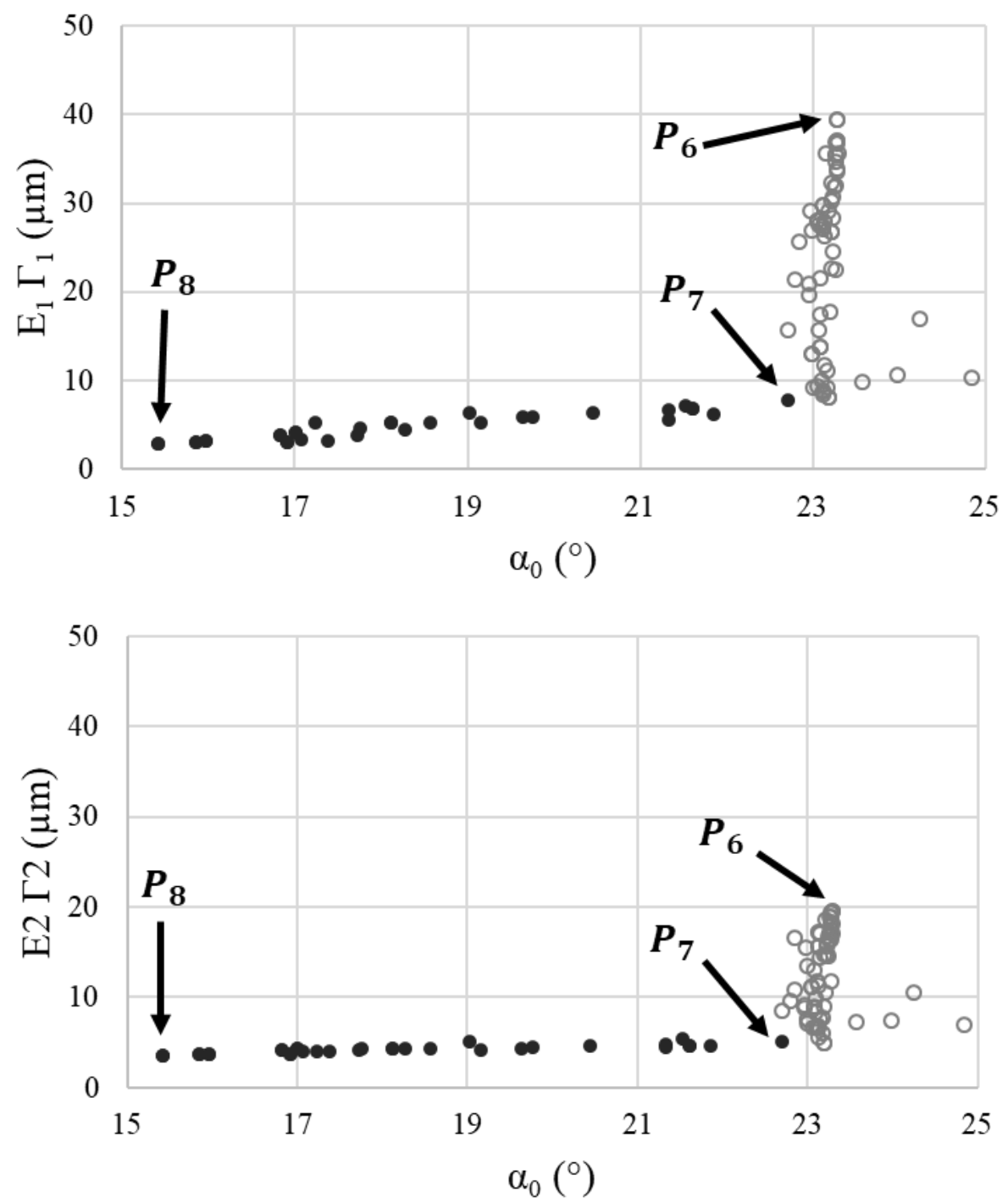

Figure 18. Solutions associated to Pareto front

The solutions associated to Pareto front are shown in Figure 18. A profile modification at the tip of the pinion larger than the one at the tip of the wheel is observed.

Figure 19 displays the different optimal Pareto fronts obtained for the optimization of $T E_{R M S}-$ $Q_{\text {total }}$ using 2, 4 and 6 design variables (see sections 6.1, 6.2, 6.3). 


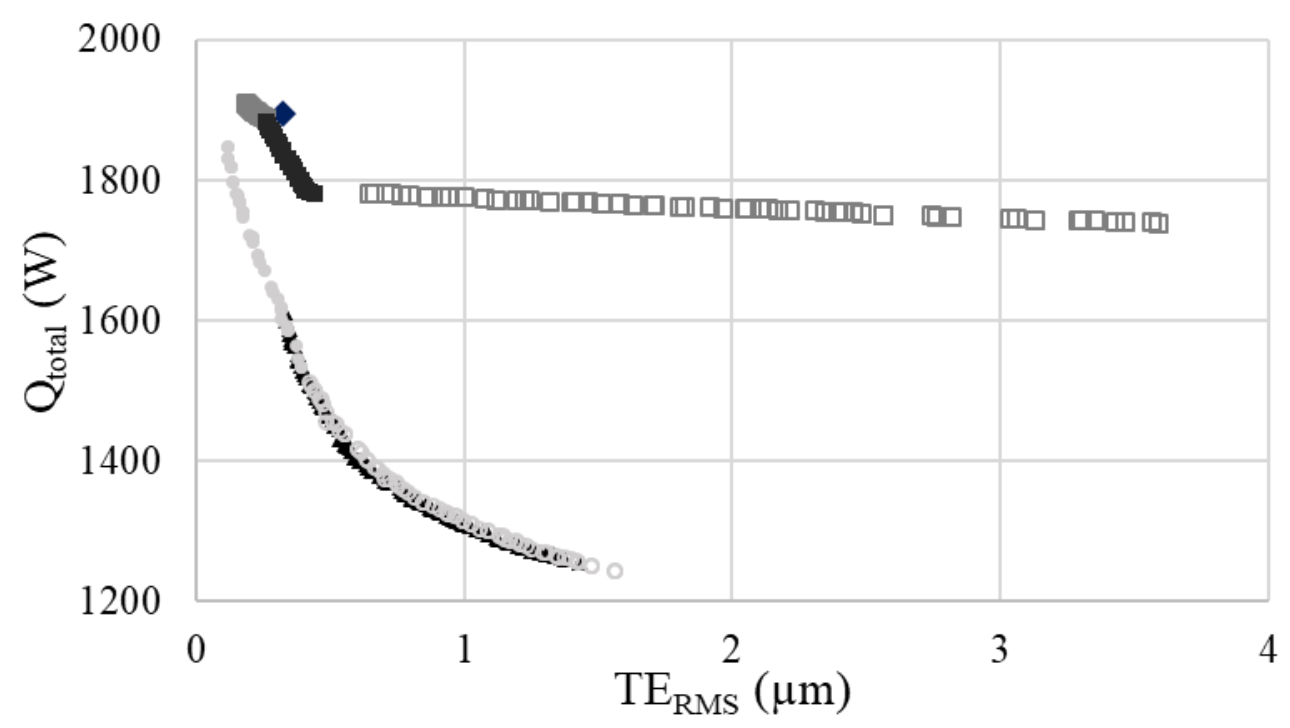

Figure 19. Pareto fronts with different design variables of $T E_{R M S}-Q_{\text {total }}$ optimization

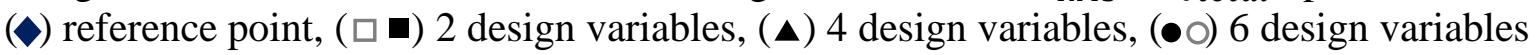

It shows that the reference point is close to the Pareto front obtained with optimization performed using two macro-geometry parameters $\left(\alpha_{0}, \beta\right)$. This optimization leads to numerous values of helix angle $\beta$. However, optimization using micro and macro-geometry parameters leads to an almost constant value of $\beta$. It also allows a large improve of the gear unit efficiency. Compared to the optimization using four micro-geometry parameters, the optimization using micro and macro-geometry parameters leads to a wider Pareto front with a lower $T E_{R M S}$ on the left side and lower power losses on the right side $Q_{\text {total }}$. Therefore, successive optimizations with firstly macro-geometry variables and secondly micro-geometry variables taken into account separately is not equivalent to an optimization with micro and macro-geometry parameters taken into account simultaneously.

\section{Conclusion}

A multi-objective optimization was performed on a single-stage helical gear unit using a genetic algorithm NSGA-II in order to improve transmission error and efficiency. Two distinct approaches have been tested concerning the power losses (tooth friction power losses vs total power losses including churning, bearing and seal power losses). The set of design variables chosen for this optimization matches macro-geometry (pressure and helix angles) and/or microgeometry parameters (profile modifications). It is firstly noticed that the distinct approaches lead to different gear design optimal parameters. It is also noticed that an optimization with macro-geometry design variables leads to Pareto front with two independent regions in terms of helix angle and pressure angle values. Taking account of micro-geometry design variables allows a significant improve of the gear unit efficiency. An optimization with both micro and macro-geometry design variables shows a continuous evolution of the objective functions corresponding to total power losses and the transmission error fluctuations.

\section{Acknowledgments:}

The authors are indebted to the institute Carnot Ingénierie@Lyon for its support and funding. 


\section{REFERENCES}

[1] H. Xu, A. Kahraman, N. E. Anderson, and D. G. Maddock, "Prediction of mechanical efficiency of parallel-axis gear pairs," ASME, Journal of Mechanical Design, vol. 129, no. 1, pp. 58-68, 2007.

[2] S. L. Harris, "Dynamic loads on the teeth of spur gears," Proceedings of Institution of Mechanical Engineering, pp. 87-112, 1958.

[3] H. Opitz, "Noise of gears," Transactions of the Royal Society, vol. 263, pp. 369-380, 1969.

[4] D. Miler, D. Žeželj, A. Lončar, and K. Vučković, "Multi-objective spur gear pair optimization focused on volume and efficiency," Mechanism and Machine Theory, vol. 125, pp. 185-195, 2018.

[5] H. Zarefar and S. N. Muthukrishnan, "Computer-aided optimal design via modified adaptive random-search algorithm," Computer-Aided Design, vol. 25, no. 4, pp. 240$248,1993$.

[6] P. Garambois, J. Perret-Liaudet, and E. Rigaud, "NVH robust optimization of gear macro and microgeometries using an efficient tooth contact model," Mechanism and Machine Theory, vol. 117, pp. 78-95, Nov. 2017.

[7] Y. Wang, "Optimized tooth profile based on identified gear dynamic model," Mechanism and Machine Theory, vol. 42, no. 8, pp. 1058-1068, 2007.

[8] N. Marjanovic, B. Isailovic, V. Marjanovic, Z. Milojevic, M. Blagojevic, and M. Bojic, "A practical approach to the optimization of gear trains with spur gears," Mechanism and Machine Theory, vol. 53, pp. 1-16, 2012.

[9] O. Buiga and C. O. Popa, "Optimal mass design of a single-stage helical gear unit with genetic algorithms," Proceedings of the Romanian Academy, Series A, vol. 13, no. 3, pp. 243-250, 2012.

[10] T. H. Chong, I. Bae, and G. J. Park, "A new and generalized methodology to design multi-stage gear drives by integrating the dimensional and the configuration design process," Mechanism and Machine Theory, vol. 37, no. 3, pp. 295-310, 2002.

[11] V. Simon, "Multi-objective optimization of hypoid gears to improve operating characteristics," Mechanism and Machine Theory, vol. 146, pp. 1-15, 2020.

[12] H. Ding, J. Tang, Y. Zhou, J. Zhong, and G. Wan, "A multi-objective correction of machine settings considering loaded tooth contact performance in spiral bevel gears by nonlinear interval number optimization," Mechanism and Machine Theory, vol. 113, pp. 85-108, 2017.

[13] G. Chandrasekaran, V. S. Sreebalaji, R. Saravanan, and J. Maniraj, "Multiobjective optimisation of bevel gear pair design using NSGA-II," Materials Today: Proceedings, vol. 16, pp. 351-360, 2019.

[14] A. Parmar, P. Ramkumar, and K. Shankar, "Macro geometry multi-objective optimization of planetary gearbox considering scuffing constraint," Mechanism and Machine Theory, vol. 154, p. 104045, 2020.

[15] I. Hüseyin Filiz, S. Olguner, and E. Evyapan, "A study on optimization of planetary gear trains,” Acta Physica Polonica A, vol. 132, no. 3, pp. 728-733, 2017. 
[16] D. Cui, G. Wang, Y. Lu, and K. Sun, "Reliability design and optimization of the planetary gear by a GA based on the DEM and Kriging model," Reliability Engineering and System Safety, vol. 203, pp. 1-13, 2020.

[17] K. Daoudi, E. M. Boudi, and M. Abdellah, "Genetic Approach for Multiobjective Optimization of Epicyclical Gear Train," Mathematical Problems in Engineering, vol. 2019, pp. 1-11, 2019.

[18] S. chul Kim, S. gon Moon, J. hyeon Sohn, Y. jun Park, C. ho Choi, and G. ho Lee, "Macro geometry optimization of a helical gear pair for mass, efficiency, and transmission error," Mechanism and Machine Theory, vol. 144, p. 103634, 2020.

[19] R. C. Sanghvi, A. S. Vashi, H. . Patolia, and R. G. Jivani, "Multi-objective optimization of two-stage helical gear train using NSGA-II," Journal of optimization, pp. 1-8, 2014.

[20] Q. Yao, "Multi-objective optimization design of spur gear based on NSGA-II and decision making," Advances in Mechanical Engineering, vol. 11, no. 3, pp. 1-8, 2019.

[21] S. Padmanabhan, S. Ganesan, M. Chandrasekaran, and V. Srinivasa Raman, "Gear pair design optimization by genetic algorithm and FEA," Proceedings of the International Conference on Frontiers in Automobile and Mechanical Engineering IEEE, pp. 396402, 2010.

[22] R. Li, T. Chang, J. Wang, X. Wei, and J. Wang, "Multi-objective Optimization Design of Gear Reducer Based on Adaptive Genetic Algorithms," in International Electronic Conference on Computer Science, 2008, pp. 273-277.

[23] M. Patil, P. Ramkumar, and K. Shankar, "Multi-objective optimization of the two-stage helical gearbox with tribological constraints," Mechanism and Machine Theory, vol. 138, pp. 38-57, 2019.

[24] A. Carbonelli, J. Perret-Liaudet, E. Rigaud, and A. Le Bot, "Particle swarm optimization as an efficient computational method in order to minimize vibrations of multimesh gears transmission," Advances in Acoustics and Vibration, pp. 1-6, 2011.

[25] A. Carbonelli, E. Rigaud, J. Perret-Liaudet, E. Pelloli, and D. Barday, "Robust optimization of a truck timing gear cascade : numerical and experimental results," in Actes CFM 2013, 21ème Congrès Français de Mécanique, 2013, pp. 1-6.

[26] M. Maatar and P. Velex, "Quasi-static and dynamic analysis of narrow-faced helical gears with profile and lead modifications," ASME, Journal of Mechanical Design, vol. 119, no. 4, pp. 474-480, 1997.

[27] M. S. Tavakoli and D. R. Houser, "Optimum profile modifications for the minimization of static transmission errors of spur gears," ASME, Journal of Mechanical Design, vol. 108, no. 1, pp. 86-94, 1986.

[28] J. A. Korta and D. Mundo, "Multi-objective micro-geometry optimization of gear tooth supported by response surface methodology," Mechanism and Machine Theory, vol. 109, pp. 278-295, 2017.

[29] D. Ghribi, J. Bruyère, P. Velex, M. Octrue, and M. Haddar, "A contribution to the design of robust profile modifications in spur and helical gears by combining analytical results and numerical simulations," ASME, Journal of Mechanical Design, vol. 134, no. 6, pp. 1-9, 2012. 
[30] A. Artoni, M. Gabiccini, M. Guiggiani, and A. Kahraman, "Multi-objective ease-off optimization of hypoid gears for their efficiency, noise, and durability performances," ASME, Journal of Mechanical Design, vol. 133, no. 12, pp. 1-9, 2011.

[31] C. I. L. Park, "Multi-objective optimization of the tooth surface in helical gears using design of experiment and the response surface method," Journal of Mechanical Science and Technology, vol. 24, no. 3, pp. 823-829, 2010.

[32] N. Driot, E. Rigaud, J. Sabot, and J. Perret-Liaudet, "Allocation of gear tolerances to minimize gearbox noise variability," Acta Acustica united with Acustica, vol. 87, no. 1, pp. 67-76, 2001.

[33] D. Ghribi, J. Bruyère, P. Velex, M. Octrue, and M. Haddar, "Multi-objective optimization of gear tooth profile modifications," Design and modeling of mechanical systems, pp. 189-197, 2013.

[34] T. A. Harris, Rolling analysis 4th Edition. New York, United States of America: John Wiley \& Sons. .

[35] D. B. Welbourn, "Fundamental Knowledge of Gear Noise," in Proceedings of the Institution of Mechanical Engineers, 1979, pp. 9-14.

[36] W. D. Mark, "Analysis of the vibratory excitation of gear systems: Basic theory," Journal of the Acoustical Society of America, vol. 63, no. 5, pp. 1409-1430, 1978.

[37] P. Velex and M. Maatar, "A mathematical model for analyzing the influence of shape deviations and mounting errors on gear dynamic behaviour," Journal of Sound and Vibration, vol. 191, no. 5, pp. 629-660, 1996.

[38] P. Velex, J. Bruyère, and D. R. Houser, "Some Analytical Results on Transmission Errors in Narrow-Faced Spur and Helical Gears: Influence Of Profile Modifications," ASME, Journal of Mechanical Design, vol. 133, no. 3, pp. 1-11, 2011.

[39] M. Lalanne, P. Berthier, and J. Der Hagopian, Mechanical Vibrations for Engineers. 1983.

[40] P. Velex, "On the relationship between gear dynamics and transmissions errors," in JSME International Conference on Motion and Power Transmissions, 2009, pp. 249254.

[41] E. Rigaud and D. Barday, "Modelling and Analysis of Static Transmission Error - Effect of Wheel Body Deformation and Interactions Between Adjacent Loaded Teeth," in 4th World Congress on Gearing and Power Transmission, 1999, vol. 3, pp. 1961-1972.

[42] M. Badaoui, V. Cahouet, F. Guillet, J. Danière, and P. Velex, "Modeling and detection of localized tooth defects in geared systems," Journal of Mechanical Design, Transactions of the ASME, vol. 123, no. 3, pp. 422-430, 2001.

[43] M. Maatar, P. Velex, and J. P. Raclot, "Some numerical methods for the simulation of geared transmission dynamic behavior formulation and assessment," Journal of Mechanical Design, Transactions of the ASME, vol. 119, no. 2, pp. 292-298, 1997.

[44] J. Durand De Gevigney, C. Changenet, F. Ville, and P. Velex, "Thermal modelling of a back-to-back gearbox test machine: Application to the FZG test rig," Proceedings of the Institution of Mechanical Engineers, Part J: Journal of Engineering Tribology, vol. 226, no. 6, pp. 501-515, 2012. 
[45] C. Changenet, X. Oviedo-Marlot, and P. Velex, "Power loss predictions in geared transmissions using thermal networks-applications to a six-speed manual gearbox," Journal of Mechanical Design, Transactions of the ASME, vol. 128, no. 3, pp. 618-625, 2006.

[46] R. C. Martins, P. S. Moura, and J. O. Seabra, "MoS2/Ti low-friction coating for gears," Tribology International, vol. 39, no. 12, pp. 1686-1697, 2006.

[47] C. Changenet, G. Leprince, F. Ville, and P. Velex, "A Note on Flow Regimes and Churning Loss Modeling," Journal of Mechanical Design, vol. 133, no. 12, pp. 1-5, 2011.

[48] C. M. C. G. Fernandes, P. M. T. Marques, R. C. Martins, and J. H. O. Seabra, "Gearbox power loss. Part II: Friction losses in gears,” Tribology International, vol. 88, pp. 309$316,2015$.

[49] E. Bruke and G. Kendall, Search methodologies: introductory tutorials in optimization and decision support techniques. Springer, 2013.

[50] J. Bruyère and P. Velex, "Derivation of Optimum Profile Modifications in Narrow-Faced Spur and Helical Gears Using a Perturbation Method," Journal of Mechanical Design, vol. 135, pp. 1-8, 2013.

[51] P. Velex and F. Ville, "An analytical approach to tooth friction losses in spur and helical gears-influence of profile modifications," Journal of Mechanical Design, Transactions of the ASME, vol. 131, no. 10, pp. 1-10, 2009.

[52] "ISO 6336 -1. Calculation of load capacity of spur and helical gears," 1996.

[53] P. Czyzak and A. Jaszkiewicz, "Pareto simulated annealing-a metaheuristicTechnique for multi-objective combinatorial optimization," Journal Of Multi-Criteria Decision Analysis, vol. 7, pp. 34-47, 1998.

[54] M. P. Hansen, "Tabu search for multiobjective optimization: MOTS," in Proceedings of the Thirteenth International Conference on Multi-Criteria Decision Making (MCDM), 1997, pp. 1-17.

[55] M. Gravel, W. L. Price, and C. Gagné, "Scheduling continuous casting of aluminum using a multiple objective ant colony optimization metaheuristic," European Journal of Operational Research, vol. 143, pp. 218-229, 2002.

[56] S. He, J. Y. Wen, E. Prempain, Q. H. Wu, J. Fitch, and S. Mann, “An improved particle swarm optimization for optimal power flow," in International conference on power system technology-POWERCON 2004, 2004, pp. 1-6.

[57] J. D. Schaffer, "Multiple objective optimization with vector evaluated genetic algorithms," in Proceedings of the 1st International Conference on Genetic Algorithms, 1985, pp. 93-100.

[58] C. M. Fonseca and P. J. Fleming, "An overview of evolutionary algorithms in multiobjective optimization," Evolutionary Computation, vol. 3, no. 1, pp. 1-16, 1995.

[59] E. Zitzler and L. Thiele, "An evolutionary algorithm for multiobjective optimization : The strength Pareto approach,” Zurich, 1998.

[60] K. Deb and T. Goel, "Controlled elitist non-dominated sorting genetic algorithms for better convergence," in International conference of evolutionary multi-criterion 
optimization, 2001, pp. 67-81.

[61] Y. Yusoff, M. S. Ngadiman, and A. M. Zain, "Overview of NSGA-II for Optimizing Machining Process Parameters,” Procedia Engineering, vol. 15, pp. 3978-3983, 2011. 
Nomenclature

\begin{tabular}{|c|c|}
\hline$a_{w}$ & Center distance $(\mathrm{mm})$ \\
\hline$b$ & Width of the gear $(\mathrm{mm})$ \\
\hline$d_{m}$ & Mean diameter of bearing $(\mathrm{mm})$ \\
\hline$e_{i}(M)$ & Total normal deviation $(\mathrm{mm})$ \\
\hline$f_{0}$ & Hydraulic loss factor \\
\hline$f_{1}$ & Factor depending on bearing characteristics \\
\hline$h$ & Heat transfer coefficient $\left(\mathrm{W} \mathrm{m}^{-2}{ }^{\circ} \mathrm{C}^{-1}\right)$ \\
\hline$k_{r i}$ & Radial stiffness of bearings $\left(\mathrm{N} \mathrm{m}^{-1}\right)$ \\
\hline$k_{a i}$ & Axial stiffness of bearings $\left(\mathrm{N} \mathrm{m}^{-1}\right)$ \\
\hline$l_{1}$ & Load applied on bearings $(\mathrm{N})$ \\
\hline$m_{0}$ & Module of gear $(\mathrm{mm})$ \\
\hline$n_{2}$ & Outward unit normal vector to wheel tooth flanks \\
\hline$q$ & Pinion and gear degree-of-freedom vector \\
\hline$x_{a}$ & Addendum coefficient \\
\hline$x_{f}$ & Dedendum coefficient \\
\hline C & Torque $(\mathrm{N} \mathrm{m})$ \\
\hline$C_{f}$ & Friction coefficient \\
\hline$C_{m}$ & Dimensionless torque \\
\hline$[C]$ & Total viscous damping matrix \\
\hline$E$ & Young modulus $(\mathrm{Pa})$ \\
\hline$E_{i}$ & actual depth of modification at tooth tip $(\mu \mathrm{m})$ \\
\hline$F_{0}$ & External load vector $(\mathrm{N})$ \\
\hline $\mathrm{F}_{r}(i, j)$ & Effort applied to the element $(i, j)$ \\
\hline$I_{m}$ & Concentrated inertial of the motor $\left(\mathrm{kg} \mathrm{m}^{2}\right)$ \\
\hline$I_{r}$ & Concentrated inertial of the receiver $\left(\mathrm{kg} \mathrm{m}^{2}\right)$ \\
\hline$[\boldsymbol{K}(t, \boldsymbol{X})]$ & Equivalent non-linear time-dependent stiffness matrix \\
\hline$[M]$ & Global constant mass matrix \\
\hline$M_{i j}$ & Point of contact line \\
\hline$M^{*}$ & Point of contact between teeth \\
\hline MOO & Multi-objective optimization \\
\hline NLTE & no-loaded static transmission error \\
\hline$P_{b a}$ & Apparent base pitch (mm) \\
\hline$P_{i}$ & Points belonging to the Pareto front for a $T E_{R M S}-Q_{\text {total }}$ optimization \\
\hline$P^{\prime}{ }_{i}$ & Points belonging to the Pareto front for a $T E_{R M S}-Q_{\text {gear }}$ optimization \\
\hline$P_{t}$ & Parent population in the $\mathrm{t}$-th generation \\
\hline$Q_{0}$ & Load-dependent power loss in the bearing (W) \\
\hline$Q_{1}$ & No-load dependent loss in the bearing (W) \\
\hline$Q_{\text {bearing }}$ & Total power loss in bearings $(\mathrm{W})$ \\
\hline$Q_{\text {churning }}$ & Churning power loss $(\mathrm{W})$ \\
\hline$Q_{\text {tooth friction }}$ & Tooth friction power loss (W) \\
\hline$Q_{\text {seal }}$ & Total power loss in shaft seal (W) \\
\hline$Q_{\text {total }}$ & Total power loss (W) \\
\hline$R_{b i}$ & Base radius $(\mathrm{mm})$ \\
\hline$R_{p i}$ & Pitch radius $(\mathrm{mm})$ \\
\hline$R_{t h}$ & Thermal resistance $\left({ }^{\circ} \mathrm{C} \mathrm{W}^{-1}\right)$ \\
\hline RMS & root mean square value \\
\hline$S_{\text {housing }}$ & Exchange surface area $\left(\mathrm{mm}^{2}\right)$ \\
\hline
\end{tabular}




\begin{tabular}{|c|c|}
\hline$S_{m}$ & Submerged surface area $\left(\mathrm{m}^{2}\right)$ \\
\hline$T_{\text {air }}$ & Air temperature $\left({ }^{\circ} \mathrm{C}\right)$ \\
\hline$T_{\text {pinion }}$ & Bulk temperature of pinion \\
\hline$T^{\prime}{ }_{1} T^{\prime}{ }_{2}$ & Length of the path of contact on the base plane (active contact length) \\
\hline$T E_{R M S}$ & RMS of transmission error fluctuation \\
\hline$V_{g}(i, j)$ & Sliding velocity $\left(\mathrm{m} \mathrm{s}^{-1}\right)$ \\
\hline$x$ & Degree-of-freedom vector for the complete system \\
\hline$Y_{B}$ & Rim thickness factor \\
\hline$Y_{D T}$ & Tooth depth factor \\
\hline$Y_{f}$ & Tooth form factor \\
\hline$Y_{S}$ & Stress correction factor \\
\hline$Y_{\beta}$ & Stress correction factor \\
\hline$Z_{i}$ & Number of teeth \\
\hline$\alpha_{0}$ & Pressure angle $\left({ }^{\circ}\right)$ \\
\hline$\beta$ & Helix angle $\left(^{\circ}\right)$ \\
\hline$\delta(M)$ & Normal displacement of the teeth due to the elasticity \\
\hline$\varepsilon_{\alpha}$ & Transverse contact ratio \\
\hline$\varepsilon_{\beta}$ & Overlap contact ratio \\
\hline$\varepsilon_{t}$ & Total contact ratio \\
\hline$\theta_{i}$ & Angular displacement \\
\hline$\vartheta$ & Oil kinematic viscosity $\left(\mathrm{m}^{2} \mathrm{~s}^{-1}\right)$ \\
\hline$v$ & Poisson's ratio \\
\hline$\rho$ & Fluid density $\left(\mathrm{kg} \mathrm{m}^{-3}\right)$ \\
\hline$\sigma$ & Bending stress $\left(\mathrm{N} \mathrm{mm}^{-2}\right)$ \\
\hline$\Delta t$ & Time step (s) \\
\hline$\Omega$ & Rotational speed $\left(\operatorname{rad~s}^{-1}\right)$ \\
\hline$\Omega_{1 \text { rigid }}$ & Rotation speed of the pinion in the ideal case $\left(\operatorname{rad~s}^{-1}\right)$ \\
\hline$\Omega_{2 \text { rigid }}$ & Rotation speed of the wheel in the ideal case $\left(\operatorname{rad~s}^{-1}\right)$ \\
\hline$\varnothing$ & Shaft diameter $(\mathrm{mm})$ \\
\hline$\Gamma$ & Dimensionless extend of profile modification \\
\hline
\end{tabular}

